JOSÉ LUIS MARINO ALFONSO

Grupo i-Ge\&ser, Universidad de Oviedo

\title{
Lugares de Interés Biogeográfico (LIB) en los Arribes del Duero zamoranos: propuesta metodológica para su inventario y valoración
}

\section{RESUMEN}

Se postula la figura de Lugar de Interés Biogeográfico (LIB) como instrumento territorial para la gestión del patrimonio vegetal a partir de una propuesta metodológica aplicada en un sector del Parque Natural de Arribes del Duero. El interés científico, paisajístico, cultural, didáctico y ecoturístico convierte a estos lugares en recursos patrimoniales que deben ser conocidos, protegidos y divulgados.

\section{RÉSUMÉ}

Lieux d'Intérêt Biogéographique dans les Arribes del Duero zamoranos: proposition méthodologique pour leur inventaire et évaluation.- La figure de Lieu d'Intérêt Biogéographique est postulée en tant qu'instrument territorial de gestion du patrimoine végétal à partir d'une proposition méthodologique appliquée dans un secteur du Parc Naturel des Arribes del Duero. L'intérêt scientifique, paysager, culturel, didactique et écotouristique fait de ces lieux des ressources patrimoniales qui doivent être connues, protégées et diffusées.

\section{INTRODUCCIÓN}

$E$ estudio de la vegetación desde una perspectiva geográfica tiene por objeto describir, localizar y explicar los paisajes vegetales y su evolución. Para ello es necesario comprender las relaciones establecidas entre las plantas con su medio, esto es, con las condiciones climáticas, edáficas, hídricas, geomorfológicas y, por supuesto, antrópicas. Esta geografía de las plantas aborda el análisis de los rasgos fisonómicos, florísticos y dinámicos de la vegetación, utilizando los métodos y técnicas (incluyendo la representación cartográfica) que han permitido consolidar la práctica biogeográfica dentro de la Geografía Física, y situarla al mismo nivel que la Geomorfología o la Climatología. Así, se han desarrollado igualmente líneas de aplicación práctica encaminadas a la consideración de la vegetación como recurso y patrimonio natural y cultural (MEAZA, 2000).
ABSTRACT

Sites of Biogeographic Interest in the Arribes del Duero zamoranos. methodological proposal for their inventory and valuation.- The figure of Site of Biogeographic Interest is postulated as a territorial instrument for the management of vegetal heritage from a methodological proposal applied in a sector of the Arribes del Duero Natural Park. The scientific, landscape, cultural, didactic and ecotouristic interest turns these sites into heritage resources that must be known, protected and disseminated.

\section{PALABRAS ClAVE/MOTS CLÉ/KeYWORDS}

Recursos naturales, patrimonio vegetal, Lugares de Interés Biogeográfico, Parque Natural de Arribes del Duero, Zamora.

Ressources naturelles, patrimoine végétal, Lieux d'Intérêt Biogéographique, Parc Naturel des Arribes del Duero, Zamora.

Natural resources, vegetal heritage, Sites of Biogeographic Interest, Arribes del Duero Natural Park, Zamora.

En este sentido, la Convención sobre la Protección del Patrimonio Natural y Cultural Mundial de la Unesco de 1972 abrió el camino a la conservación integral de la naturaleza, definiendo el término de patrimonio natural como el conjunto de bienes y recursos de la naturaleza fuente de diversidad biológica y geológica. Paradójicamente, mientras la biología de la conservación evolucionó rápidamente en nuestro país durante las décadas de 1970 y 1980, la geoconservación no se difundió hasta comienzos de la actual centuria; y sin embargo, ha sido esta última la que más logros ha obtenido desde la perspectiva de ordenación, gestión y puesta en valor del patrimonio geológico y geomorfológico ${ }^{1}$. Por el contrario, desde esta

1 Baste señalar algunos proyectos relacionados con el patrimonio geológico y geomorfológico realizados a diferente escala: Global Geosites, Red Internacional de Geoparques, Inventario Español de Lugares de Interés Geológico (IELIG), inventario regional de la Fundación Patrimonio Natural de Castilla y León, in- 
misma óptica, los estudios geográficos sobre patrimonio vegetal han tenido un menor desarrollo ${ }^{2}$, puesto que generalmente ha primado un enfoque biológico aplicado a la realización de inventarios y catálogos de ecosistemas, flora, recursos genéticos, recursos naturales y espacios protegidos (PIQUERAS, 2001; VILCHES, 2007; SERVICIO DE PROTECCIÓN Y CONSERVACIÓN DE LA NATURALEZA DE LA REGIÓn DE MuRCIA, 2009; SERRA, 2016).

Por tanto, resulta ineludible ponderar desde un enfoque geográfico el término de patrimonio vegetal, entendido como el conjunto de formaciones y taxones vegetales, paisajes, áreas y lugares que presentan un interés biogeográfico y que, por su especial singularidad, relevancia, diversidad, calidad, valor escénico e interés socioeconómico y etnográfico, merecen una atención preferente en cuanto a su conocimiento, conservación y divulgación. De forma auxiliar, se hace necesario desarrollar un instrumento de ordenación y gestión de base territorial a través del cual canalizar la puesta en valor como recurso de este patrimonio biogeográfico con fines científicos, culturales, didácticos, educativos, estéticos y ecoturísticos. Se propone para tal fin la figura de Lugar de Interés Biogeográfico (LIB), definido como un espacio que alberga una formación vegetal o conjunto de comunidades vegetales de especial interés monumental, escénico, ecológico, pedagógico o científico, y que resulta esencial en la composición morfológica y en la dinámica y evolución del paisaje o espacio natural.

\section{OBJETIVOS, FUENTES Y METODOLOGÍA}

Este artículo tiene como objetivo fundamental inventariar y valorar Lugares de Interés Biogeográfico (LIB) en un área representativa de los Arribes del Duero zamoranos, siguiendo un método de trabajo puesto en práctica en la misma zona de estudio para la selección y evaluación

ventario provincial del patrimonio geológico zamorano por parte del Instituto de Estudios Zamoranos (JORDÁ, 2006) e inventarios comarcales o aplicados a espacios naturales protegidos (SERRANO y otros, 2006 y 2009; GonZÁLEZ TRUEBA y SERRANO, 2008; MARINO y otros, 2019).

${ }^{2}$ Cabe destacar la metodología Lanbioeva (Landscape Biogeographic Evaluation) desarrollada a partir de las propuestas iniciales de Meaza y Cadiñanos (2000) y Cadiñanos y otros (2002). Ha sido aplicada en diferentes contextos geográficos para la valoración de la vegetación a efectos de ordenación y gestión así como en estudios sectoriales que ponen el foco en el análisis del paisaje vegetal como recurso patrimonial (ver por ejemplo los trabajos de Díaz y Lozano, 2017; Lozano y otros, 2015 y 2018a; Beato, 2018). Cebe destacar también otras metodologías como las utilizadas en los trabajos cuantitativos acerca de la biodiversidad de Whittaker (1972) o Benton (2001), así como aquellas otras basadas en fórmulas de valoración como la de los servicios ambientales que ofrecen los distintos ecosistemas (CONSTANZA y otros, 1997). de Lugares de Interés Geomorfológico (LIG) (MARINO y otros, 2017a). Se incluye, por consiguiente, dentro de un proyecto más ambicioso que tiene como último propósito sistematizar una metodología que permita la identificación y valoración de Lugares de Interés Natural (LIN) a partir de la evaluación de sus valores de tipo geomorfológico, biogeográfico y paisajístico.

Por tanto, el presente trabajo se hace cargo del análisis biogeográfico aplicando, sin embargo, un método deudor de los trabajos desarrollados en los ámbitos geológico y geomorfológico por Martín y otros (2010 y 2012), Serrano y González (2005), González Trueba, (2006), Serrano y otros (2006 y 2009), González y Serrano (2008), Serrano y Ruiz (2007) y González y otros (2014) en lo que se refiere a la organización de la información recogida y la valoración de los lugares de interés. En su adaptación a la disciplina biogeográfica se han tenido en cuenta las propuestas de Arozena y Molina (2000) para organizar los niveles jerárquicos de las unidades de paisaje vegetal y algunos aspectos del método de valoración de estas, sintetizado por Lozano y otros (2018b).

Se desgranan a continuación las fases metodológicas propuestas para el inventario y valoración de Lugares de Interés Biogeográfico (LIB) en su aplicación a un sector del Parque Natural de Arribes del Duero situado en la comarca zamorana de Sayago.

1.') Análisis de los factores geográficos. Cualquier aproximación al estudio de la vegetación debe tener en cuenta la influencia que los factores geográficos tienen en la distribución de las plantas. Se requiere por tanto de un análisis de la influencia directa e indirecta del relieve y sus formas, del clima y sus variaciones altitudinales, de los recursos hídricos disponibles a lo largo del año, de la litología y los suelos asociados a ella y, en última instancia, pero no menos importante, de la acción humana pasada y actual a la cual se debe, en gran medida, la organización definitiva del paisaje vegetal.

2. ${ }^{\text {) }) ~ E s t u d i o ~ f i s o n o ́ m i c o, ~ f l o r i ́ s t i c o ~ y ~ d i n a ́ m i c o ~ d e ~ l a ~}$ vegetación. La caracterización biogeográfica parte de las fuentes cartográficas disponibles, en este caso, el Mapa Forestal de España 1:200.000 (1990), el Atlas Forestal de Castilla y León (2007), el Mapa de Vegetación de Castilla y León 1:400.000 (2009) y el Banco de Datos de la Naturaleza, que ofrece la cartografía del Mapa Forestal de España a escala 1:50.000 (2006). Sin embargo, son bien conocidas las carencias de estos mapas realizados a escala inadecuada, sin trabajo de campo propio y con graves deficiencias en la delimitación de unidades (BEATO y otros, 2017). Por consiguiente, estas lagunas deben superarse mediante el trabajo de campo, consistente en la 
realización de transectos e inventarios de vegetación para determinar la composición florística y estructura fisonómica utilizando criterios fitosociológicos de abundanciadominancia (BRAUN-BLANQUET, 1979).

3. $\left.{ }^{a}\right)$ Representación cartográfica y clasificación de las unidades de paisaje vegetal. A partir del estudio de la estructura y dinámica de la vegetación es posible reconocer y establecer las unidades de vegetación, representadas cartográficamente en un mapa detallado a escala 1:25.000 sobre la base ortofotográfica del PNOA (2015). El mapa permite indagar en los patrones de jerarquía espacial que sigue la vegetación, por lo que se convierte en una herramienta fundamental para organizar las unidades de paisaje vegetal en niveles jerárquicos: grandes unidades de paisaje, comunidades vegetales y facies de vegetación. El elemento básico lo constituye la comunidad vegetal, identificada con una formación vegetal encabezada por uno o varios taxones con representatividad territorial. Resultado de las discontinuidades propias de cada comunidad vegetal surgen las facies de vegetación, que puestas en relación engloban unidades de mayor tamaño que aportan contexto al paisaje, definiendo así las grandes unidades de paisaje.

4..) Inventario y descripción de LIB. Se procede en esta fase a la identificación de las formaciones vegetales más reseñables y su clasificación en lugares o elementos y en representativos o singulares, para establecer a continuación el listado definitivo de LIB. Para cada espacio catalogado se prepara una ficha descriptiva en la que se sintetizan los aspectos fundamentales desde el punto de vista biogeográfico (tipo de LIB, caracteres biogeográficos, estructura fisonómica, composición florística, dinámica de la vegetación, interés y atribución del LIB), así como aquellos otros relacionados con su posible uso y gestión (contenido cultural, accesibilidad, grado de interés, estado de conservación, usos actuales, comunicaciones, infraestructuras, impactos y situación legal).

5. a) Valoración de LIB. Se lleva a cabo una triple evaluación en cada uno de los LIB seleccionados: valores intrínsecos o científicos (puramente biogeográficos), valores añadidos o culturales y valores de uso y gestión. En estos dos últimos se mantienen las mismas escalas de puntuación aplicadas en la evaluación de $\mathrm{LIG}^{3}$, mientras

\footnotetext{
3 Los valores añadidos o culturales evaluados son: consideración escalar paisajística y estética, elementos patrimoniales, aspectos culturales, fases históricas de uso y ocupación, contenidos pedagógicos y docentes, niveles educativos, áreas científicas con valor significativo, representatividad científica, contenido turísticos y capacidad de atracción turística. Se otorga un punto por cada elemento presente hasta un máximo que varía entre 5 y 10. La calificación total obtenid sobre 70 puntos se pondera sobre 10 . Por su parte, los valores de uso y gestión
}

que para los primeros se ha desarrollado una escala de puntuación propia adaptada al estudio biogeográfico. En concreto se han evaluado los siguientes valores intrínsecos: diversidad vegetal, riqueza florística, representatividad, estructura vertical, cobertura arbolada, madurez, singularidad vegetal, flora amenazada, función ecológica y valor etnobotánico ${ }^{4}$. En cada valor se ha establecido una escala de 1 a 5 , y posteriormente la puntuación total obtenida de 50 puntos se barema sobre 10 para comparar con los otros dos tipos de valores.

6. ) Diagnosis y propuestas de uso y gestión para LIB. A partir del análisis de los resultados obtenidos se ofrece una orientación de uso y gestión de cada LIB, que en la mayoría de los casos se centra en la interpretación del patrimonio biogeográfico orientada a su aprovechamiento científico, didáctico y ecoturístico.

\section{III. ÁREA DE ESTUDIO}

Se conoce como Arribes del Duero a la estrecha, profunda y prolongada garganta fluvial abierta por el río homónimo en su tramo internacional, esto es, en la frontera hispano-lusa. En efecto, a lo largo de $120 \mathrm{~km}$ el río Duero se encaja progresivamente en el rígido zócalo paleozoico hasta profundizar su cauce $500 \mathrm{~m}$ sobre el nivel topográfico de la penillanura zamorano-salmantina. No obstante, el comienzo de este gran cañón puede situarse antes de La Raya ${ }^{5}$, inmediatamente aguas abajo de la ciudad de Zamora (625 m s.n.m.), cuando el río Duero deja atrás las campiñas abiertas sobre los blandos materiales sedimentarios de su cuenca terciaria, y comienza a abrirse paso entre las resistentes y duras rocas plutónicas y metamórficas del reborde occidental de la Meseta. A un ritmo aproximado de $3,5 \mathrm{~m} / \mathrm{km}$ el río va profundizando su entalladura hasta alcanzar los $125 \mathrm{~m}$ s.n.m. en Barca d'Alva, última localidad fronteriza donde el curso recupera su sentido este-oeste para adentrarse de-

\footnotetext{
considerados son: accesibilidad, fragilidad, vulnerabilidad, intensidad de uso, riesgo de degradación, impactos, condiciones de observación, límites de cambio aceptables, servicios y equipamientos y potencial económico. Para su evaluación se emplea una escala del 0 al 2: el 2 representa un valor positivo que facilita el uso y el 0 uno negativo que dificulta su gestión. La cifra máxima hasta 20 puntos también se pondera sobre 10 (MARINO y otros, 2017a,p. 33).

${ }^{4}$ Los valores de singularidad vegetal, flora amenazada y valor etnobotánico se han determinado a partir de los principales catálogos y guías disponibles (RUIZ, 1991; SANTOS y otros, 2006; Decreto 63/2007 del Boletín Oficial de Castilla y León; GALLEGo y GALLEGO, 2008). El resto de los valores científicos se han evaluado a tenor de la información recogida durante la fase de trabajo de campo.

${ }^{5}$ Con este nombre (A Raia en portugués) se conoce a la zona fronteriza entre España y Portugal.
} 


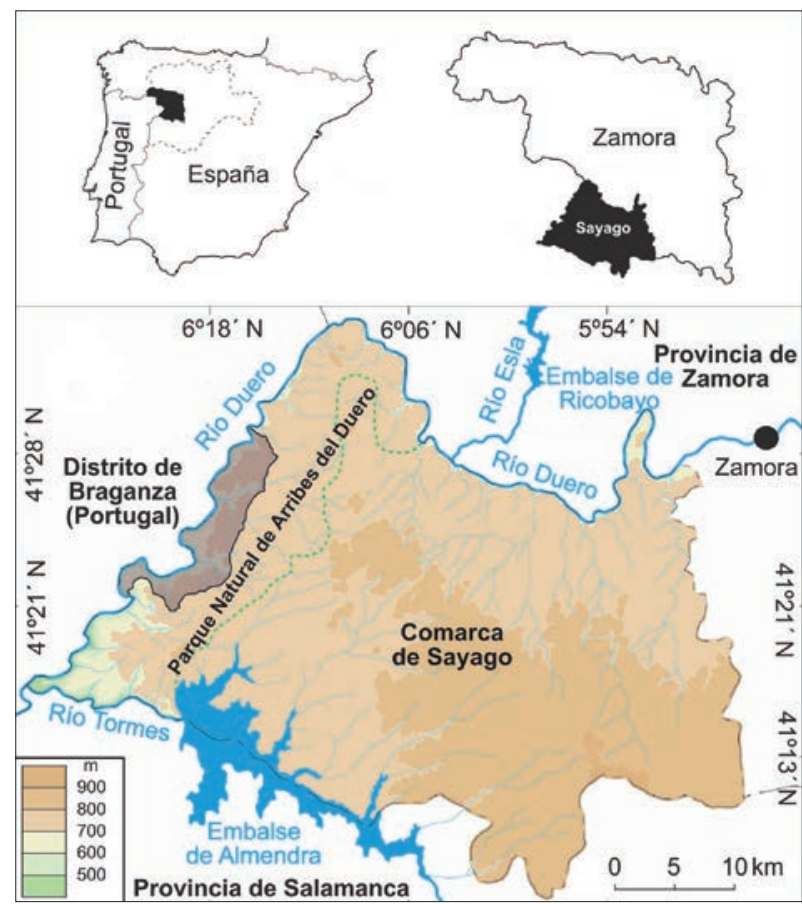

FIG. 1. Mapa de localización del área de estudio dentro de los límites del Parque Natural de Arribes del Duero en la zamorana comarca de Sayago. Elaboración propia a partir de la base topográfica del IGN.

finitivamente en Portugal en busca de su desembocadura atlántica.

Este congosto hendido provoca una suavización del régimen térmico, generando un microclima dentro de la fría región castellano-leonesa que ha permitido el desarrollo de una vegetación termófila y unos cultivos típicamente mediterráneos en bancales abiertos sobre las pronunciadas laderas. Por la concurrencia de estas singulares condiciones naturales, el espacio geográfico en cuestión se incluyó en 1991 en el Plan de Espacios Naturales Protegidos de Castilla y León, con la denominación de Arribes del Duero. Una década más tarde se aprobó el Plan de Ordenación de los Recursos Naturales (Decreto 164/2001, de 7 de junio, de la Junta de Castilla y León), donde se proponía la figura de Parque Natural como la más adecuada. Un año después, esta declaración se hizo oficial por parte de las Cortes de Castilla y León (Ley 5/2002, de 11 de abril). De forma paralela, los Arribes del Duero también se integraron en la Red Natura 2000 como Zona Especial de Conservación (ZEC) y Zona de Especial Protección para las Aves (ZEPA). El último reconocimiento se produjo en 2015 , con la declaración por parte de la Unesco como Reserva de la Biosfera Transfronteriza bajo la denominación de Meseta Ibérica, junto al vecino Parque Natural do Douro Internacional y otros espacios naturales protegidos del distrito portugués de Braganza y la provincia española de Zamora, conformando uno de los espacios protegidos más extensos de Europa (1.132.607 ha).

En lo que se refiere al área de estudio seleccionada dentro de los límites del Parque Natural de Arribes del Duero (106.105 ha), se ha optado, dada la magnitud del espacio protegido, por un sector representativo del tramo zamorano del parque donde están presentes todas las formaciones vegetales de los Arribes del Duero zamoranos. En concreto, la zona analizada comprende un sector ubicado en la comarca del Bajo Sayago entre las localidades de Miranda do Douro (al norte) y Pinilla de Fermoselle (al sur). Unos $20 \mathrm{~km}$ a lo largo del curso del río Duero, a partir del cual se ha delimitado en su margen izquierda una estrecha banda paralela al mismo de 3.000 $\mathrm{m}$ de anchura aproximadamente. En total, la zona de estudio abarca unas 6.000 ha, repartidas de forma desigual entre tres términos municipales (Torregamones de Sayago, Fariza y Villar del Buey) a los que pertenecen siete pequeñas poblaciones (Badilla, Cozcurrita, Fariza, Mámoles, Palazuelo de Sayago, Fornillos de Fermoselle y Pinilla de Fermoselle) que suman un total de 529 habitantes (Fig. 1).

\section{LOS FACTORES GEOGRÁFICOS: NATURALES Y HUMANOS}

\section{LOS FACTORES GEOMORFOLÓGICOS}

La singular configuración geomorfológica de los Arribes del Duero determina la enorme influencia que estos factores ejercen de forma indirecta en la cubierta vegetal, por cuanto las condiciones climáticas, hídricas, edáficas y antrópicas derivan en gran medida de la evolución morfológica que el relieve ha seguido. A saber, con el basculamiento de la Meseta Central española hacia el oeste, la depresión terciaria del Duero pasó de un régimen endorreico a otro exorreico, desatándose una ola de erosión regresiva procedente desde el océano Atlántico que terminó por capturar esta cuenca (SOLÉ, 1958). La extrema dureza de los materiales cristalinos del zócalo paleozoico que afloran en el reborde occidental de la Meseta Septentrional provocó que esta evacuación se efectuara a través de una profunda y estrecha garganta fluvial, excavada a favor de las principales líneas de debilidad estructural (MARTÍN-SERRANO, 1988). Del mismo modo, el encajado lecho fluvial del Duero se convirtió en el ni- 
CUADRO I. Síntesis termométrica comparativa entre la garganta fluvial del Duero y la penillanura zamorano-salmantina aplicada en la zona de estudio

\begin{tabular}{|c|c|c|}
\hline Indicador termométrico & Garganta fluvial del Duero & Penillanura zamorano-salmantina \\
\hline Temperatura media anual & Entre 13 y $17^{\circ} \mathrm{C}$ & Entre 12 y $12,4^{\circ} \mathrm{C}$ \\
\hline Temperatura media de enero & De 5 a $6,9^{\circ} \mathrm{C}$ & De 4 a $4,4^{\circ} \mathrm{C}$ \\
\hline Temperatura media de julio & De 22 a $23,9^{\circ} \mathrm{C}$ & De 21 a $21,9^{\circ} \mathrm{C}$ \\
\hline Temperatura media de las mínimas de enero & De 1 a $2{ }^{\circ} \mathrm{C}$ & De 0 a $0,9^{\circ} \mathrm{C}$ \\
\hline Temperatura media de las máximas de julio & De 30 a $30,9{ }^{\circ} \mathrm{C}$ & De 28 a $28,9^{\circ} \mathrm{C}$ \\
\hline Día de la última helada de primavera & Del 26 de febrero al 29 de marzo & Del 30 de marzo al 12 de abril \\
\hline Día de la primera helada de otoño & Del 16 de noviembre al 7 de diciembre & Del 6 de noviembre al 15 de noviembre \\
\hline Periodo libre de heladas & 235-283 días & 215-235 días \\
\hline
\end{tabular}

Elaboración propia a partir del Atlas agroclimático de Castilla y León (2013)

vel de base a partir del cual se reactivó, mediante una pequeña red fluvial de tipo dendrítico, un proceso erosivo que comenzó a desmantelar progresivamente las alteritas que recubrían la penillanura zamorano-salmantina, a la par que exhumaba un complejo paisaje granítico.

Por tanto, debe tomarse en consideración la gran trascendencia de este accidente físico en el resto de los factores ambientales. Primero, en la acentuación de los contrastes topoclimáticos asociados a los cambios altitudinales o la exposición de las vertientes. Segundo, en la influencia ejercida sobre la evolución de la corteza edáfica, al haber sido intensamente rebajada a partir de una red ortogonal de fracturas que han guiado el encajamiento de los arroyos. Tercero, en la propia configuración hidrográfica resultante, caracterizada por el predominio de pequeños afluentes con poca capacidad para aportar recursos hídricos. Y cuarto, en la propia profundización del cauce, que llega a alcanzar los $300 \mathrm{~m}$ de encajamiento, resultando unas pronunciadas vertientes que imponen un serio obstáculo al aprovechamiento humano.

No obstante, antes de analizar detalladamente la influencia directa de estos factores, conviene no minusvalorar el papel que por sí mismo poseen las formas del relieve en la configuración del paisaje vegetal. Así, las llanuras erosivas que nivelan a distintas altitudes el zócalo constituyen el agro cerealista y vitícola. Los relieves residuales que a modo de montes-isla descuellan sobre el monótono perfil de la penillanura (sierros cuarcíticos y berrocales graníticos) acogen ralas formaciones arbóreas con sotobosques densos destinadas a la explotación silvopastoril. Las propias arenas procedentes de la denudación de muchos de estos relieves residuales rellenan a su vez estrechas llanuras aluviales que permiten el desarrollo de bosques galería y nutritivos pastos para el ganado. Por otro lado, la proximidad a la garganta fluvial supone un incremento de la capacidad erosiva de los arroyos que surcan la penillanura, por lo que profundas y grandes masas de granito escasamente alterado comienzan a aflorar (dorsos de ballena, domos, bolos, torres) ${ }^{6}$. De este modo, las limitaciones impuestas al uso agrario, unido a la acentuación de las pendientes, ha permitido el desarrollo y salvaguarda de variadas formaciones arbóreas con un alto grado de densidad.

\section{LOS FACTORES CLIMÁTICOS}

Los dos grandes conjuntos geomorfológicos resultantes de la evolución del relieve, esto es, la garganta fluvial del Duero y la penillanura zamorano-salmantina en la que la primera se inscribe, dan lugar a su vez a dos áreas topoclimáticas netamente diferenciadas por su régimen térmico (Cuadro I). Por un lado, la penillanura presenta unas condiciones muy similares al resto de la cuenca del Duero, con inviernos muy fríos y largos y veranos cortos y cálidos. Por su parte, la garganta fluvial acorta y suaviza los inviernos, mientras que alarga y hace calurosos los veranos, fruto de un gradiente térmico vertical más alto de lo normal debido al comportamiento del propio cañón como acumulador térmico (GARCíA, 1986; CALONGE, 1990).

Por el contrario, en lo que se refiere al régimen pluviométrico, no existen contrastes entre ambas áreas topoclimáticas. Las precipitaciones se reparten de forma uniforme, observándose un progresivo aunque ligero aumento hacia el suroeste de la región. La alineación NE-SO de

\footnotetext{
${ }^{6}$ Para un conocimiento más detallado de la organización morfológica del relieve y su evolución puede consultarse en la revista Estudios Geográficos un artículo que lleva por título «Geomorfología de los Arribes del Duero zamoranos» (MARINO y otros, 2018b).
} 
E R Í A

CUADRO II. Evolución mensual de indicadores climáticos e hídricos en el Salto de Castro

\begin{tabular}{|c|c|c|c|c|c|c|c|c|c|c|c|c|}
\hline & $\mathrm{E}$ & F & M & A & My & $\mathrm{J}$ & $\mathrm{Jl}$ & $\mathrm{Ag}$ & $\mathrm{S}$ & $\mathrm{O}$ & $\mathrm{N}$ & $\mathrm{D}$ \\
\hline $\mathrm{Tm}$ & 4,3 & 6,0 & 8,7 & 10,9 & 14,7 & 19,4 & 23,1 & 22,5 & 19,2 & 14,0 & 8,2 & 5,0 \\
\hline TM' & 9,0 & 11,7 & 15,7 & 17,5 & 21,7 & 27,2 & 32,0 & 31,1 & 27,0 & 20,5 & 13,4 & 9,6 \\
\hline $\mathrm{Tm}$ & $-0,3$ & 0,4 & 2,0 & 4,4 & 7,8 & 11,6 & 14,2 & 13,9 & 11,5 & 7,5 & 3,1 & 0,5 \\
\hline AT & 9,3 & 11,3 & 13,4 & 13,1 & 13,9 & 15,6 & 17,8 & 17,2 & 15,5 & 13,0 & 10,3 & 9,1 \\
\hline I & 0,80 & 1,32 & 2,31 & 3,25 & 5,12 & 7,79 & 10,5 & 9,75 & 7,67 & 4,75 & 2,12 & 1 \\
\hline Etp & 0,4 & 0,6 & 1,0 & 1,3 & 2,0 & 2,9 & 3,7 & 3,6 & 2,9 & 1,8 & 0,9 & 0,4 \\
\hline $\mathrm{K}$ & 24,9 & 24,9 & 30,9 & 33,3 & 37,5 & 37,8 & 38,1 & 37,7 & 31,2 & 28,8 & 24,6 & 24,0 \\
\hline ETP & 9,9 & 14,9 & 30,9 & 43,3 & 75,0 & 109,6 & 140,9 & 135,7 & 90,4 & 51,8 & 22,1 & 9,6 \\
\hline $\mathrm{P}$ & 80,4 & 63,0 & 46,5 & 53,6 & 52,8 & 36,3 & 15,2 & 15,5 & 36,0 & 58,0 & 75,8 & 79,4 \\
\hline P-ETP & 70,5 & 48,1 & 15,6 & 10,3 & $-22,2$ & $-73,3$ & $-125,7$ & $-120,2$ & $-54,4$ & 6,2 & 53,7 & 69,8 \\
\hline $\mathrm{Sd}$ & 0 & 0 & 0 & 0 & $-22,2$ & $-95,5$ & $-221,2$ & $-341,4$ & $-395,8$ & 0 & 0 & 0 \\
\hline RU & 100 & 100 & 100 & 100 & 80 & 39 & 11 & 3 & 2 & 8,2 & 61,9 & 100 \\
\hline VR & 0 & 0 & 0 & 0 & 20 & 41 & 28 & 8 & 1 & $-6,2$ & $-53,7$ & $-38,1$ \\
\hline ETR & 9,9 & 14,9 & 30,9 & 43,3 & 72,8 & 77,3 & 43,2 & 23,5 & 37,0 & 51,8 & 22,1 & 9,6 \\
\hline $\mathrm{D}$ & 0 & 0 & 0 & 0 & 2,2 & 32,3 & 97,7 & 112,2 & 53,4 & 0 & 0 & 0 \\
\hline S & 70,5 & 48,1 & 15,6 & 10,3 & 0 & 0 & 0 & 0 & 0 & 0 & 0 & 31,7 \\
\hline E & 35,2 & 41,6 & 28,6 & 19,4 & 9,7 & 4,8 & 2,4 & 1,2 & 0,6 & 0,3 & 0,1 & 15,9 \\
\hline
\end{tabular}

Elaboración propia a partir de los datos ofrecidos por el Centro Meteorológico Territorial de Castilla y León.

los cercanos relieves montañosos del interior de Portugal (Sierra de Mogadouro) actúa de barrera orográfica, dejando a sotavento de los flujos del oeste toda la penillanura zamorano-salmantina. Por el contrario, los vientos húmedos e inestables de componente suroeste barren sin obstáculo alguno la comarca, canalizándose a través de la propia garganta fluvial por su trazado NE-SO. Así, se llegan a superar ligeramente los $600 \mathrm{~mm}$ de media anual, repartidos entre 71 y 76 jornadas de lluvia concentradas fundamentalmente en invierno y otoño (ambas estaciones son las más lluviosas con $185 \mathrm{~mm}$ ), mientras que en primavera $(155 \mathrm{~m}) \mathrm{y}$, sobre todo, en verano $(55 \mathrm{~mm})$, se reducen drásticamente (NAFRÍA y otros, 2013).

De este modo, siguiendo la clasificación climática de Köppen ${ }^{7}$, resultan dos tipos de clima: un clima Csa, típicamente mediterráneo en la garganta fluvial del Duero; y otro clima Csb, de tendencia oceánica con verano seco sobre la penillanura zamorano-salmantina. Así pues, los factores climáticos explican en gran medida la encrucijada biológica engendrada en este rincón occidental de la región castellano-leonesa, que hace de los Arribes del

\footnotetext{
${ }^{7}$ Köppen definió esta clasificación en 1900, estableciendo los intervalos de temperatura y precipitación a partir de su influencia sobre la distribución de la vegetación y de la actividad humana. Posteriormente fue modificada por el propio Köppen (1936) y adaptada por Antonio López Gómez y Julia López Gómez a España en 1959.
}

Duero un área de contacto a modo de bisagra entre los sistemas forestales íbero-atlánticos e íbero-mediterráneos (SÁNCHEZ RODRÍGUEZ, 1984).

\section{LOS FACTORES HÍDRICOS}

El balance hídrico resulta de gran importancia para el establecimiento de uno u otro tipo de especie o formación vegetal y su desarrollo o actividad vegetativa. A partir de los regímenes de pluviosidad y temperatura se establece el ciclo anual de excedentes y déficits de agua ${ }^{8}$.

De forma general, durante el invierno y hasta mediados de la primavera se prolonga la etapa excedentaria. Sin embargo, en los primeros meses la paralización de la actividad vegetativa es total, puesto que las temperaturas no llegan a alcanzar $\operatorname{los} 7,5^{\circ} \mathrm{C}$. Cuando se supera este um-

\footnotetext{
${ }^{8}$ Se han explotado los datos ofrecidos por la estación termopluviométrica de Salto de Castro, al ser la más cercana a la zona de estudio. Está situada a $710 \mathrm{~m}$ s.n.m. y ofrece una serie histórica ampliamente superior al treintenio (19612002). En concreto, se han calculado, siguiendo la metodología de Thornthwaite (1948), los valores mensuales para los siguientes indicadores climáticos e hídricos: temperatura media (Tm), temperatura media de las máximas (TM'), temperatura media de las mínimas (Tm'), amplitud térmica (AT), índice calórico (I), evapotranspiración diaria (Etp), iluminación (K), evapotranspiración potencial (ETP), precipitación media $(\mathrm{P})$, sumatorio del déficit $(\mathrm{Sd})$, reserva útil (RU), variación de la reserva útil (VR), evapotranspiración real (ETR), déficit (D), superávit $(\mathrm{S})$ y escorrentía $(\mathrm{E})$
} 
bral, a partir de marzo, la actividad vegetativa es plena. Desde mediados de la primavera hasta fines del verano se extiende la etapa deficitaria. Así, cuando termina mayo la actividad biológica comienza a descender, a pesar de que siguen cubiertas las necesidades hídricas mínimas requeridas por las plantas. Pero ya no se produce el excedente de agua que sería necesario para impedir la sequía que hace acto de presencia a finales de junio, prolongándose hasta gran parte de septiembre. En este mes se produce una ligera recuperación hídrica que todavía no resulta suficiente para compensar a las plantas tras el período estival. Esta recuperación es plena en los meses otoñales de octubre y noviembre, que son los del reequilibrio entre el déficit estival y el superávit invernal (Cuadro II).

No obstante, cabe constatar la existencia de otros factores que interactúan en el balance hídrico. El primero de ellos tiene que ver con las características litoedáficas, puesto que la porosidad de los suelos arenosos que se desarrollan sobre las alteritas acrecienta el déficit hídrico durante el verano, mientras que la impermeabilidad del sustrato granítico genera un súbito aumento de la escorrentía desde el momento en el que los acuíferos desbordan de agua. Este fenómeno, relativamente frecuente en otoño e invierno, se desencadena tras el paso de una familia de borrascas atlánticas arrastrada por vientos de componente SO. El segundo de los factores tiene implicaciones humanas, al estar relacionado con la construcción de los Saltos del Duero ${ }^{9}$. Efectivamente, el agua embalsada puede modificar el balance hídrico al incrementarse la humedad del aire, como deja entrever la frecuencia de días en los que se producen nieblas de evaporación y episodios de rocío en el interior del cañón fluvial.

\section{LOS FACTORES EDÁFICOS}

Como es bien sabido, el reconocimiento de los rasgos más significativos del perfil edáfico permite una adecuada comprensión de la vegetación, puesto que aspectos como la profundidad, el color, la textura, la estructura y otras propiedades físico-químicas de los suelos ejercen una gran influencia en ella. En general, en la zona de estudio predominan los suelos pardos ácidos, asentados sobre el roquedo granítico y metamórfico que sustenta la

\footnotetext{
${ }^{9}$ Los Saltos del Duero constituyen un proyecto hidroeléctrico realizado en el tramo internacional del río homónimo a partir del acuerdo hispano-luso de 1927. Al amparo de este convenio se construyeron un total de nueve presas y embalses: Ricobayo, Villalcampo, Castro, Miranda, Picote, Bemposta, Almendra, Aldeadávila y Saucelle.
}

penillanura, y los litosoles asociados a las fuertes pendientes de las laderas en la garganta fluvial. De forma puntual, aparecen suelos rojos fersialíticos sobre exiguos materiales terciarios colgados y suelos de tipo hidromorfo en los depósitos aluviales cuaternarios ${ }^{10}$.

Los suelos pardos ácidos son suelos silíceos con un perfil $\mathrm{A}(\mathrm{B}) \mathrm{C}$ y una textura arenosa por la simple desagregación en arenas por alteración del roquedo granítico y metamórfico. Están ocupados por abiertos montes de encina o rebollo y cultivos cerealistas o matorrales de recuperación allí donde el laboreo ha sido abandonado. En cualquier caso, son suelos mediocres debido a su alta acidez, poca profundidad, alta pedregosidad, deficiencias en calcio y fósforo y estructura arenosa con poca capacidad de retención de agua. Por ello, necesariamente deben ser neutralizados mediante el aporte de enmiendas cálcicas que permiten el desarrollo de algunos cultivos leñosos (vid, almendro y olivo).

Allí donde la inclinación del terreno se acentúa, se desencadena un fuerte proceso erosivo que impide la evolución de los suelos. Surgen de este modo los litosoles, suelos con un perfil (A)C donde el horizonte humífero está constituido exclusivamente por restos de la roca madre y tiene escaso espesor $(10 \mathrm{~cm})$. La mayor parte de las veces, granitos y gneises afloran masivamente de forma directa. Las condiciones son tan extremas que solo aquellas comunidades vegetales más resistentes son capaces de sobrevivir, caso de los enebrales. Solo donde la pendiente del terreno se reduce los suelos pueden evolucionar y alcanzar cierto grado de eutrofización al resguardar formaciones más o menos boscosas: quejigares en umbrías y cornicabrales en solanas.

La acumulación de depósitos terciarios vinculados al primitivo río Tormes permitió, bajo unas condiciones paleoclimáticas de tipo subtropical, el desarrollo de una alteración química que terminó generando un suelo rojo fersialítico. Estos suelos presentan un perfil $\mathrm{ABC}$, donde sobresale un horizonte $\mathrm{B}$ de color rojo vivo por el continuo lavado de arcillas del horizonte superior. La eliminación de esta tierra fina da lugar a la formación de una masa superficial de cantos rodados. La relativa profundidad, humedad, fertilidad y aireación de estos suelos ácidos acoge las escasas masas de alcornoque presentes en los Arribes del Duero (JovelLAR, 2008).

Por último, sobre el fondo de los pequeños valles planos mal avenados que surcan la penillanura se desarrollan suelos hidromorfos temporales o pseudogley. La imper-

\footnotetext{
${ }^{10}$ La explicación de los factores edáficos se hace siguiendo los criterios de la clasificación genética francesa (DUCHAUFOUR, 1984).
} 
meabilidad de la roca madre provoca su encharcamiento durante los periodos lluviosos, mientras que la porosidad de las arenas que rellenan el fondo de los valles provoca rápidamente el agotamiento de las reservas de agua. Las condiciones para el desarrollo de la vegetación son por tanto muy desfavorables, limitándose a exiguas fresnedas riparias y pastizales de diente.

\section{LOS FACTORES ANTRÓPICOS}

La primigenia cubierta vegetal fue alterada desde los primeros momentos de la ocupación humana del territorio $^{11}$. Desde la década de 1960 la presión demográfica ha ido disminuyendo de forma paulatina hasta alcanzar niveles mínimos en la actualidad ${ }^{12}$, fruto de un proceso de despoblamiento y envejecimiento característico del interior peninsular. No obstante, las duras condiciones impuestas por el medio natural al aprovechamiento agrario provocaron un nivel de tecnificación y especialización inferior al resto de las comarcas rurales mesetarias. Así, hasta bien entrada la década de 1970 la economía de la comarca todavía se basaba en una explotación tradicional en la que agricultura y ganadería se complementaban.

La agricultura se practicaba en las cortinas, parcelas privadas cerradas por paredes de piedra situadas en las inmediaciones de los núcleos de población. Se alternaban cultivos con destino al consumo tanto humano (hortalizas y patatas) como animal (forrajes y nabos). Se completaba la producción agrícola en las tierras más alejadas, situadas en las proximidades de la garganta fluvial, y si era posible se bajaba hasta la misma orilla del río Duero. Estas tierras eran de carácter comunal y se destinaban al cultivo de cereal, mayoritariamente centeno. Por consiguiente, de la roturación solo se salvaban los terrenos más improductivos, donde crecían enebros y encinas.

La ganadería se llevaba a cabo en los prados inmediatos al pueblo, integrados en el cinturón de cortinas. Estos prados particulares de diente y siega eran utilizados cuando se agotaban los pastos ribereños de los valles y los rastrojos de los montes comunales. En su mayor parte, sustentaban una cabaña ganadera compuesta por ove-

\footnotetext{
${ }^{11}$ La configuración del paisaje rural sayagués a través de sucesivas fases históricas ha sido abordada por numerosos autores, como Costa (1902), Cabo (1956), Crespo (1968) y Sánchez Gómez (1991), haciendo referencias más o menos detalladas al proceso de antropización y los cambios en el paisaje vegetal.

12 En 2018, según datos del INE, entre las siete localidades ubicadas dentro de la zona de estudio sumaban 529 habitantes repartidos de la siguiente forma: Fariza, 198; Badilla, 83; Palazuelo de Sayago, 81; Fornillos de Fermoselle, 57; Pinilla de Fermoselle, 53; Mámoles, 33; Cozcurrita, 24.
}

jas, cabras y animales de tiro (vacas y asnos). El monte arbolado (encinares, enebrales, rebollares y alcornocales) ofrecía madera, leña, bellota y corcho.

Desde los años ochenta del pasado siglo el abandono de las actividades agrarias comenzó primeramente por las tierras comunales. Progresivamente las antiguas tierras cerealistas fueron siendo ocupadas por matorrales leguminosos, jarales, cantuesares y berceales, a la par que los montes arbolados de encina y enebro más lejanos se iban cerrando. La tendiente especialización ganadera hacia el sector ovino ha mantenido cierta presión sobre los pastos y montes comunales más cercanos, así como sobre el terrazgo cerealista y los prados ubicados en las cortinas aledañas a los pueblos. De este modo, se han liberado importantes espacios por donde progresa la regeneración natural de la vegetación.

\section{RESULTADOS}

\section{ESTUDIO FISONÓMICO, FLORÍSTICO Y DINÁMICO DE LA VEGETACIÓN}

Los condicionantes físicos, tal y como se ha expuesto previamente, ejercen un papel de enorme trascendencia en la configuración del paisaje vegetal de los Arribes del Duero zamoranos. Los contrastes topoclimáticos derivados de la singular configuración geomorfológica explican la presencia de dos pisos bioclimáticos: el mesomediterráneo, por debajo de los 700 m s.n.m. y adscrito a la garganta fluvial; y el supramediterráneo, por encima de los 700 m s.n.m. y vinculado a la penillanura. La influencia sobre la vegetación es tan determinante que una y otra unidad de paisaje se corresponden con sectores biogeográficos distintos: subsector ribaduriense y sector salmantino respectivamente (NAVARRO y VALLE, 1987).

Las cálidas y escarpadas vertientes de la garganta fluvial acogen una vegetación de tipo termófilo rica en especies típicamente mediterráneas, como la encina, el enebro y la cornicabra. La limitación impuesta a los usos agrarios por la precariedad edáfica ha favorecido el desarrollo y preservación de masas sorprendentemente densas, en franco estado de recuperación tras la reducción de la carga ganadera.

Por contra, las frías planicies de la penillanura potencian el desarrollo de una vegetación marcescente protagonizada por el rebollo. Sin embargo, el conocido proceso de frutalización del paisaje mediterráneo (GoNZÁLEZ, 1992) ha beneficiado la extensión de la encina en detrimento de este último. En cualquier caso, la acción 
CUADRO III. Estudio florístico de las unidades de paisaje vegetal

\begin{tabular}{|c|c|c|c|c|c|c|c|c|c|c|c|c|c|c|c|c|c|c|c|}
\hline \multirow[b]{2}{*}{ Estrato } & \multirow[b]{2}{*}{ Especie vegetal } & \multicolumn{18}{|c|}{ Código } \\
\hline & & 1 & 2 & 3 & 4 & 5 & 6 & 7 & 8 & 9 & 10 & 11 & 12 & 13 & 14 & 15 & 16 & 1718 & 19 \\
\hline \multirow{6}{*}{ 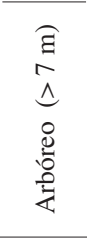 } & Quercus ilex subsp. ballota & 4 & 4 & 3 & 3 & & & & & & 2 & & & & & & & & \\
\hline & Juniperus oxycedrus subsp. badia & & 2 & 1 & 1 & & & 5 & 2 & 1 & & & & & & & & & \\
\hline & Quercus suber & & & & & & & & & & 3 & 4 & & & & & & & \\
\hline & Quercus pyrenaica & & & & & & & & & & & & & & 3 & & & & \\
\hline & Fraxinus angustifolia & & & & & & & & & & & & & & & 3 & & & \\
\hline & Quercus faginea subsp. broteroi & & & & & & & & & & & & 4 & & & & & & \\
\hline \multirow{12}{*}{ 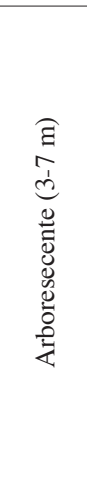 } & Quercus ilex subsp. ballota & 3 & 3 & 2 & 1 & 4 & 4 & 1 & & & 2 & & & & & & & & \\
\hline & Juniperus oxycedrus subsp. badia & & 1 & 1 & 1 & & & 3 & 2 & 1 & 1 & & & & & & & & \\
\hline & Pistacia terebinthus & 1 & 1 & & & & & & & & & & & 1 & & & & & \\
\hline & Celtis australis & 1 & 1 & & & & & & & & & & & & & & & & \\
\hline & Quercus suber & & & & & & & & & & 2 & 3 & & & & & & & \\
\hline & Quercus x morisii & & & & & & & & & & 1 & & & & & & & & \\
\hline & Quercus faginea subsp. faginea & & & & & & & & & & 1 & & & & & & & & \\
\hline & Quercus pyrenaica & & & & & & & & & & 1 & & & & 3 & & & & \\
\hline & Fraxinus angustifolia & & & & & & & & & & & & & & & 2 & & & \\
\hline & Salix atrocinerea & & & & & & & & & & & & & & & 1 & & & \\
\hline & Salix salviifolia & & & & & & & & & & & & & & & 1 & & & \\
\hline & Quercus faginea subsp. broteroi & & & & & & & & & & & & 3 & & & & & & \\
\hline \multirow{20}{*}{ 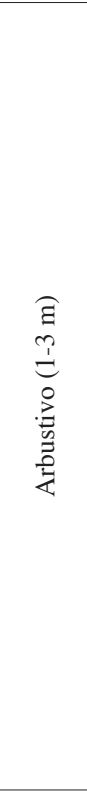 } & Cistus ladanifer & 1 & 3 & & 4 & & & & & & 2 & & & & & & & 3 & \\
\hline & Cytisus scoparius & 1 & 2 & 1 & 1 & & & 1 & & & 1 & & 1 & & & & & & \\
\hline & Pistacia terebinthus & 1 & 1 & & & & & 1 & & & & & & 4 & & & & & \\
\hline & Celtis australis & 1 & 1 & & & & & & & & & & & & & & & & \\
\hline & Ficus carica & & 1 & & & & & & & & & & & & & & & & \\
\hline & Olea europaea subsp. sylvestris & & 1 & & & & & & & & & & & & & & & & \\
\hline & Quercus ilex subsp. ballota & 1 & 1 & & & 2 & & 1 & & & & & & & & & & & \\
\hline & Acer monspessulanum & 1 & & & & & & & & & & & & & & & & & \\
\hline & Cytisus multiflorus & 1 & & 2 & & & & & & & 1 & & & & & & & & \\
\hline & Quercus suber & & & & & & & & & & & 1 & & & & & & & \\
\hline & Quercus pyrenaica & & & & & & & & & & & & & & 2 & & & & \\
\hline & Genista falcata & & & & & & & & & & & & & & 1 & & & & \\
\hline & Genista florida subsp. polygaliphylla & & & & & & & & & & & & 1 & & 1 & & & & \\
\hline & Adenocarpus complicatus & & & & & & & & & & & & & & 1 & & & & \\
\hline & Fraxinus angustifolia & & & & & & & & & & & & & & & 1 & & & \\
\hline & Salix fragilis & & & & & & & & & & & & & & & 1 & & & \\
\hline & Salix purpurea & & & & & & & & & & & & & & & 1 & & & \\
\hline & Salix triandra & & & & & & & & & & & & & & & 1 & & & \\
\hline & Juniperus oxycedrus subsp. badia & & 1 & & & & & 2 & 2 & 1 & & & & & & & & & \\
\hline & Quercus faginea subsp. broteroi & & & & & & & & & & & & 2 & & & & & & \\
\hline \multirow{10}{*}{ 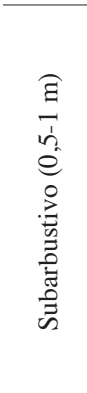 } & Cistus ladanifer & 1 & 2 & & 3 & & & & & & 3 & 2 & & & & & & 3 & \\
\hline & Cytisus scoparius & 1 & 1 & 1 & 1 & & & 3 & 1 & & 1 & & 1 & & & 2 & 3 & & \\
\hline & Ficus carica & & 1 & & & & & & & & & & & & & & & & \\
\hline & Olea europaea subsp. Sylvestris & & 1 & & & & & & & & & & & & & & & & \\
\hline & Rhus coriaria & & 1 & & & & & & & & & & & & & & & & \\
\hline & Vitis vinifera & & 1 & & & & & & & & & & & & & & & & \\
\hline & Genista hystrix & 1 & 2 & 1 & 1 & & & 1 & 1 & & 1 & & & & & & 1 & 1 & \\
\hline & Cytisus multiflorus & 1 & 1 & 2 & 1 & & & 2 & 3 & & 1 & & & & & & 4 & & \\
\hline & Quercus ilex subsp. ballota & 1 & & & & 1 & & & & & & & & & & & & & \\
\hline & Acer monspessulanum & 1 & & & & & & & & & & & & & & & & & \\
\hline
\end{tabular}


CUADRO III. Estudio florístico de las unidades de paisaje vegetal

\begin{tabular}{|c|c|c|c|c|c|c|c|c|c|c|c|c|c|c|c|c|c|c|c|c|}
\hline \multirow[b]{2}{*}{ Estrato } & \multirow[b]{2}{*}{ Especie vegetal } & \multicolumn{19}{|c|}{ Código } \\
\hline & & 1 & 2 & 3 & 4 & 5 & 6 & 7 & 8 & 9 & 10 & 11 & 12 & 13 & 14 & 15 & 16 & 17 & 18 & 19 \\
\hline \multirow{9}{*}{ 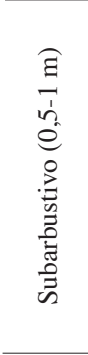 } & Daphne gnidium & 1 & 1 & 1 & & & & 1 & 1 & & 1 & & & & & & 1 & & & \\
\hline & Quercus pyrenaica & & & & & & & & & & & & & & 1 & & & & & \\
\hline & Genista falcata & & & & & & & & & & & & & & 1 & & & & & \\
\hline & Genista florida subsp. polygaliphylla & & & & & & & & & & & & 1 & & & & & & & \\
\hline & Adenocarpus complicatus & & & & & & & & & & & & & & 1 & & & & & \\
\hline & Juniperus oxycedrus subsp. badia & & 1 & & & & & & 1 & 1 & & & & & & & & & & \\
\hline & Pistacia terebinthus & & & & & & & 1 & & & & & & 3 & & & & & & \\
\hline & Lavandula stoechas & & & & & & & & 3 & & & & & & & & & & & \\
\hline & Quercus faginea subsp. broteroi & & & & & & & & & & & & 1 & & & & & & & \\
\hline \multirow{39}{*}{ 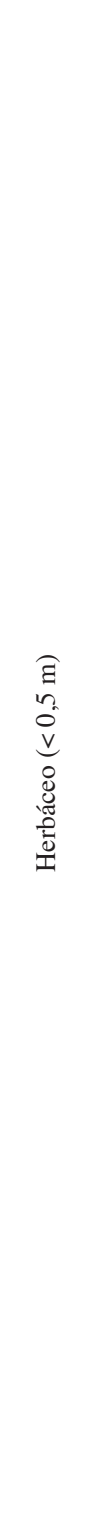 } & Cistus ladanifer & & 2 & & 3 & & & & & & 2 & 2 & & & & & & 3 & & \\
\hline & Lavandula stoechas & 1 & 2 & 2 & 2 & 2 & & 2 & 3 & 3 & 2 & 2 & & 3 & 1 & & 3 & 2 & 5 & \\
\hline & Quercus ilex subsp. ballota & 1 & 1 & 1 & 1 & & & 2 & & & & & & & & & & & & \\
\hline & Juniperus oxycedrus subsp. badia & & 1 & & 1 & & & 2 & 1 & 1 & & & & & & & & & & \\
\hline & Ruscus aculeatus & 1 & & & & & & & & & & & & & & & & & & \\
\hline & Cytisus scoparius & 1 & & & 1 & 1 & & & 1 & 1 & 1 & & 2 & 1 & 1 & & 2 & & & \\
\hline & Cytisus multiflorus & 1 & & & 1 & 1 & & & 3 & 3 & 1 & & & 1 & 1 & & 3 & & 1 & \\
\hline & Cytisus striatus & 1 & & & & & & & & & & & & & & & & & & \\
\hline & Cistus salviifolius & 1 & & & & & & & & & & & & & & & & & & \\
\hline & Adenocarpus complicatus & 1 & & & & & & & & & & & & & 1 & & & & & \\
\hline & Osyris alba & 1 & & & & & & & & & & & & & & & & & & \\
\hline & Santolina rosmarinifolia & 1 & & & & & & & & & & & & & & & & & & \\
\hline & Helichrysum stoechas & 1 & & & & & & & & & & & & & & & & & & \\
\hline & Thymus zygis & & & 1 & 1 & & & 1 & & & & & & 1 & & & 1 & 1 & 2 & \\
\hline & Rubus ulmifolius & 1 & & & & & & & & & & & & & & 1 & & & & \\
\hline & Saponaria officinalis & 1 & & & & & & & & & & & & & & & & & & \\
\hline & Ranunculus ficaria & 1 & & & & & & & & & & & 1 & & & 1 & & & & \\
\hline & Viola riviniana & 1 & & & & & & & & & & & 1 & & & 1 & & & & \\
\hline & Solanum dulcamara & 1 & & & & & & & & & & & & & & 1 & & & & \\
\hline & Polypodium vulgare & 1 & & & & & & & & & & & 1 & & & & & & & \\
\hline & Pteridium aquilinum & 1 & & & & & & & & & & & & & & & & & & \\
\hline & Acer monspessulanum & 1 & & & & & & & & & & & & & & & & & & \\
\hline & Genista hystrix & & & & & & & & 1 & 1 & 1 & 1 & & 1 & 1 & & 1 & 1 & 1 & \\
\hline & Thymus mastichina & 1 & 1 & 1 & & & & 1 & 1 & 1 & & 1 & & 1 & & & 1 & 1 & 2 & \\
\hline & Daphne gnidium & & & & & 1 & & & 1 & 1 & & 1 & & & & & 1 & & 1 & \\
\hline & Halimium umbellatum subsp. visosum & & 2 & & & & & 1 & 1 & 1 & & 1 & & & & & & & 1 & \\
\hline & Quercus suber & & & & & & & & & & & 1 & & & & & & & & \\
\hline & Asparagus acutifolius & 1 & & & & & & 1 & & & & & & & & & & & & \\
\hline & Jasminun fruticans & 1 & & & & & & & & & & & & & & & & & & \\
\hline & Paeonia broteroi & 1 & & & & & & & & & & & 1 & & & & & & & \\
\hline & Lonicera etrusca & 1 & & & & & & & & & & & & & & & & & & \\
\hline & Rubia peregrina & 1 & & & & & & & & & & & & & & & & & & \\
\hline & Arenaria montana & 1 & & & & & & & & & & & & & & & & & & \\
\hline & Sedum forsteranum & 1 & & & & & & & & & & & & & & & & & & \\
\hline & Stipa gigantea & 1 & & & & & & 1 & 1 & 1 & & & & 1 & 1 & & & & & 4 \\
\hline & Quercus pyrenaica & & & & & & & & & & & & & & 3 & & & & & \\
\hline & Genista falcata & & & & & & & & & & & & & & 1 & & & & & \\
\hline & Genista florida subsp. polygaliphylla & & & & & & & & & & & & 2 & & 1 & & & & & \\
\hline & E. barnadesii subsp. dorsisericeum & & 2 & & & & & & & & & & & & 1 & & & & & \\
\hline
\end{tabular}


CUADRO III. Estudio florístico de las unidades de paisaje vegetal

\begin{tabular}{|c|c|c|c|c|c|c|c|c|c|c|c|c|c|c|c|c|c|c|c|c|}
\hline \multirow[b]{2}{*}{ Estrato } & \multirow[b]{2}{*}{ Especie vegetal } & \multicolumn{19}{|c|}{ Código } \\
\hline & & 1 & 2 & 3 & 4 & 5 & 6 & 7 & 8 & 9 & 10 & 11 & 12 & 13 & 14 & 15 & 16 & 17 & 18 & 19 \\
\hline \multirow{12}{*}{ 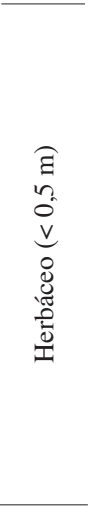 } & Clematis vitalba & & & & & & & & & & & & & & & 1 & & & & \\
\hline & Lythrum salicaria & & & & & & & & & & & & & & & 1 & & & & \\
\hline & Epilobium hirsutum & & & & & & & & & & & & & & & 1 & & & & \\
\hline & Rosa corymbifera & & & & & & & & & & & & & & & 1 & & & & \\
\hline & Pistacia terebinthus & & & & & & & 1 & & & & & & 3 & & & & & & \\
\hline & Daphne gnidium & & & & & & & & & & & & & 1 & & & & & & \\
\hline & Lonicera peryclimenum & & & & & & & & & & & & 1 & & & & & & & \\
\hline & Cistus laurifolius & & & & & & & & & & & & 1 & & & & & & & \\
\hline & Primula vulgaris & & & & & & & & & & & & 1 & & & & & & & \\
\hline & Quercus faginea subsp. broteroi & & & & & & & & & & & & 1 & & & & & & & \\
\hline & Herbáceas diversas & 2 & 3 & 4 & & & & 4 & 3 & 2 & & & 3 & 3 & 3 & 2 & 2 & 3 & 3 & 3 \\
\hline & Gramíneas & & & & & 5 & 5 & & & & & & & & & & & & & \\
\hline \multirow{3}{*}{ 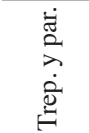 } & Bryonia cretica & 1 & & & & & & & & & & & & & & & & & & \\
\hline & Tamus comunis & 1 & & & & & & & & & & & 1 & & & & & & & \\
\hline & Arcenthobium oxicedri & & & & & & & 1 & 1 & 1 & & & & & & & & & & \\
\hline
\end{tabular}

Los códigos se corresponden con las facies de vegetación establecidas en el cuadro VI. Elaboración propia.

CUADRO IV. Estudio de la fisonomía y dinámica de las unidades de paisaje vegetal

\begin{tabular}{|c|c|c|c|c|c|c|c|c|c|c|}
\hline \multirow[b]{2}{*}{ Código } & \multicolumn{2}{|c|}{ Arbóreo (> 7 m) } & \multicolumn{2}{|c|}{ Arborescente (3-7 m) } & \multicolumn{2}{|c|}{ Arbustivo (1-3 m) } & \multicolumn{2}{|c|}{ Subarbustivo $(0,5-1 \mathrm{~m})$} & \multicolumn{2}{|c|}{ Herbáceo $(<0,5$ m) } \\
\hline & A-D & Dinámica & A-D & Dinámica & A-D & Dinámica & A-D & Dinámica & A-D & Dinámica \\
\hline 1 & 4 & $=$ & 3 & + & 4 & + & 4 & + & 5 & + \\
\hline 2 & 4 & $=$ & 3 & + & 4 & + & 3 & + & 5 & + \\
\hline 3 & 3 & $=$ & 2 & $=$ & 2 & + & 3 & + & 5 & + \\
\hline 4 & 3 & $=$ & 1 & $=$ & 5 & + & 4 & + & 5 & + \\
\hline 5 & & & 4 & $=$ & 2 & $=$ & 1 & $=$ & 5 & $=$ \\
\hline 6 & & & 4 & $=$ & & & & & 5 & $=$ \\
\hline 7 & 5 & + & 4 & + & 3 & + & 4 & + & 5 & + \\
\hline 8 & 2 & $=$ & 2 & $=$ & 2 & $=$ & 5 & + & 5 & + \\
\hline 9 & 1 & $=$ & 1 & $=$ & 1 & $=$ & 1 & $=$ & 5 & + \\
\hline 10 & 4 & $=$ & 4 & + & 3 & + & 4 & + & 4 & + \\
\hline 11 & 4 & $=$ & 3 & $=$ & 1 & $=$ & 2 & - & 3 & - \\
\hline 12 & 4 & + & 3 & + & 2 & + & 2 & + & 5 & + \\
\hline 13 & & & 1 & + & 4 & + & 3 & + & 5 & + \\
\hline 14 & 3 & $=$ & 3 & $=$ & 3 & + & 3 & + & 5 & + \\
\hline 15 & 3 & + & 2 & + & 2 & + & 2 & + & 3 & + \\
\hline 16 & & & & & & & 5 & - & 5 & - \\
\hline 17 & & & & & 3 & - & 4 & - & 5 & - \\
\hline 18 & & & & & & & & & 5 & - \\
\hline 19 & & & & & & & & & 5 & + \\
\hline
\end{tabular}

Los códigos se corresponden con las facies de vegetación establecidas en el Cuadro VI. Elaboración propia. 


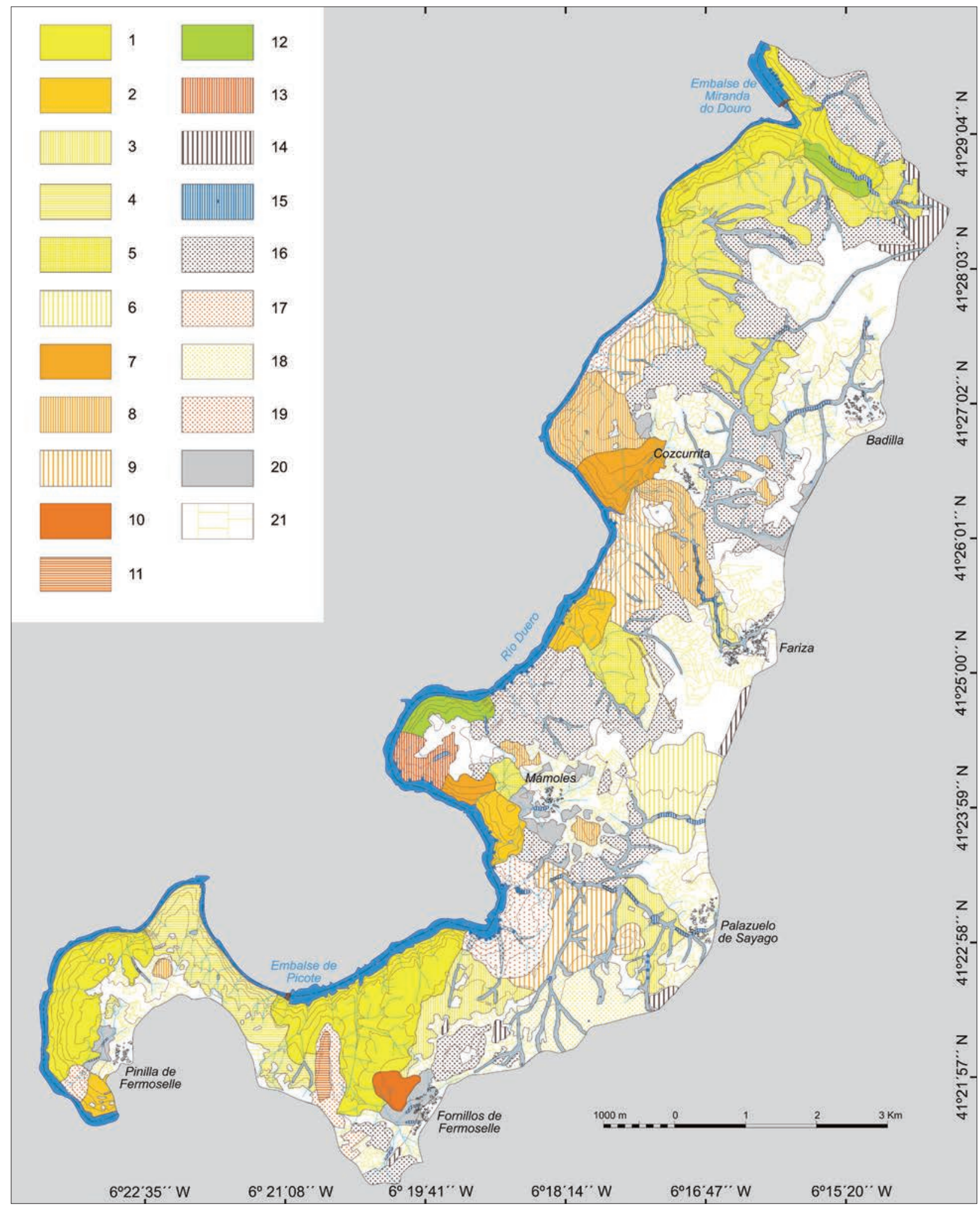

FIG. 2. Mapa de unidades de paisaje vegetal. La numeración de la cartela se corresponde con los 19 códigos de las facies de vegetación establecidos en el Cuadro VI (además, el 20 representa los pastizales y el 21 los cultivos). Elaboración propia a partir de la ortofotografía del PNOA (2015) y el trabajo de campo. 
CUADRO V. Organización de los niveles jerárquicos de las unidades de paisaje vegetal. Comunidades vegetales

\begin{tabular}{|c|c|c|c|}
\hline Código & Denominación & Serie de vegetación & Denominación local \\
\hline A & Encinar & Genisto hystricis-Querceto rotundifoliae & Carrascal, Carrasquera, Encinal \\
\hline B & Enebral & Junipero oxicedri-Querceto rotundifoliae & Jimbral, Nebral \\
\hline $\mathrm{C}$ & Alcornocal & Sanguisorbo hybridae-Querceto suberis & Jebreral, Zufral \\
\hline $\mathrm{D}$ & Quejigar & Sanguisorbo hybridae-Querceto suberis & Cajigal \\
\hline $\mathrm{E}$ & Cornicabral & Junipero oxicedri-Querceto rotundifoliae & Fidiguera \\
\hline $\mathrm{F}$ & Rebollar & Genisto falcatae-Querceto pyrenaicae & Robledal \\
\hline G & Fresneda & Ficario ranunculoidis-Fraxineto angustifoliae & Fresneda \\
\hline $\mathrm{H}$ & Matorral de leguminosas & $\begin{array}{l}\text { Genisto hystricis-Cytisetum multiflori } \\
\text { Genisto (floridae) polygaliphyllae-Cytisetum scopari } \\
\text { Genisto hystricis-Echinospartetum lusitanici }\end{array}$ & $\begin{array}{l}\text { Escobal, Escobonar, } \\
\text { Piornal, Cambrional }\end{array}$ \\
\hline I & Jaral & Lavandulo pedunculatae-Genistetum hystricis & Jaral \\
\hline $\mathrm{J}$ & Cantuesar & Lavandulo sampaianae-Cytisetum multiflori & Tomillar \\
\hline $\mathrm{K}$ & Berceal & Arrhenathero bulbosi-Stipion gigantae & Barceguera, Barcegal \\
\hline
\end{tabular}

Elaboración propia.

humana ha tenido un papel capital en la organización del paisaje vegetal, a través de la roturación de tierras para el cultivo y la generación de pastizales y prados, el adehesamiento de las masas originales o la propia selección de especies. Asociado al abandono agrario se ha generado un proceso de matorralización que invade antiguos terrones cerealistas y sotobosques de escobas, piornos, cantuesos, tomillos, jaras y barcegos.

En las áreas de transición se cobijan, bajo condiciones ecológicas muy singulares, quejigares y alcornocales. Los primeros se acantonan sobre umbrosas vertientes, lo suficiente frías para el alcornoque, frescas para la encina y templadas para el rebollo. Los segundos buscan la humedad del sustrato sedimentario en que se asientan y su pureza y densidad obedece al aprovechamiento tradicional del corcho. Al margen quedan las fresnedas salpicadas de sauces, que a modo de bosques galería se desarrollan por las riberas. Su grado de naturalidad aumenta conforme se acercan los arroyos a su desembocadura en el río Duero.

En definitiva, la interacción de los factores naturales y humanos ha dado lugar a un mosaico vegetal tremendamente heterogéneo en cuanto a fisonomía, composición florística, articulación espacial, modos de asociación y estructura interna y dinámica, que ha requerido de un minucioso y prolongado trabajo de campo $^{13}$. Fruto de este trabajo se han reconocido y establecido diecinueve unidades de vegetación en función de criterios fisonómi-

\footnotetext{
${ }^{13}$ Una caracterización biogeográfica más profunda se puede consultar en la revista Cuadernos Geográficos (MARINO y otros, 2017b).
}

cos, florísticos y dinámicos. A cada una de ellas se le ha asignado su correspondiente sininventario, elaborado a partir de inventarios propios realizados en el campo. Los resultados se expresan de forma sintetizada en los cuadros III y IV ${ }^{14}$.

\section{REPRESENTACIÓN CARTOGRÁFICA Y CLASIFICACIÓN DE LAS UNIDADES DE PAISAJE VEGETAL}

El análisis fisonómico y florístico ha permitido sintetizar espacialmente las unidades resultantes de la interacción con los factores geográficos, mediante la cartografía de unidades de paisaje vegetal en diferentes niveles. Así concebido, el mapa permite conocer la distribución espacial de la vegetación y su clasificación en las categorías jerárquicas en que se organizan dichas unidades.

El mapa de unidades de paisaje vegetal está diseñado a partir de los principios establecidos por Gaussen $(1966)^{15}$. Así, mediante una gama cromática establecida

\footnotetext{
${ }^{14}$ El estudio florístico se basa en la abundancia-dominancia que cada especie que forma parte de la unidad de vegetación en cuestión tiene en cada uno de los estratos, mientras que el estudio fisonómico y dinámico se efectúa por estratos, analizando la abundancia-dominancia del conjunto de especies de cada uno de los estratos y su dinámica dentro del conjunto. Los valores y signos utilizados se interpretan de la siguiente manera: 1 (menos de $10 \%$ ), 2 (entre 10 y $24 \%$ ), 3 (entre 25 y $49 \%$ ), 4 (entre 50 y $75 \%$ ), 5 (más de $75 \%$ ) en el caso de la abundanciadominancia $;=($ equilibrio $),+$ (progresiva $),-($ regresiva $)$ para la dinámica.

${ }^{15}$ Este biogeógrafo francés desarrolló una cartografía de la vegetación en la que combinaba dos criterios: la representación de las series y pisos de vegetación mediante una secuencia cromática vinculada a las condiciones ambientales, y la estructura fisonómica a través de la intensidad del color o el uso de tramas.
} 
CUADRO VI. Organización de los niveles jerárquicos de las unidades de paisaje vegetal. Facies de vegetación

\begin{tabular}{|c|c|c|}
\hline Código & Denominación & Características \\
\hline 1 & Encinar & Formación arbórea cerrada y monoespecífica de Quercus ilex subsp. ballota \\
\hline 2 & Encinar con enebro & $\begin{array}{l}\text { Formación arbórea cerrada dominada por Quercus ilex subsp. ballota acompañada puntualmente } \\
\text { por Juniperus oxycedrus subsp. badia }\end{array}$ \\
\hline 3 & Encinar con matorral leguminoso & $\begin{array}{l}\text { Formación arbórea abierta y monoespecífica de Quercus ilex subsp. ballota con sotobosque } \\
\text { denso dominado por matorral leguminoso (Cytisus scoparius, Cytisus multiflorus y Genista } \\
\text { hystrix) }\end{array}$ \\
\hline 4 & Encinar con matorral de jara & $\begin{array}{l}\text { Formación arbórea abierta y monoespecífica de Quercus ilex subsp. ballota con sotobosque } \\
\text { denso dominado por Cistus ladanifer }\end{array}$ \\
\hline 5 & Encinar con pastizal & $\begin{array}{l}\text { Formación arbórea abierta y monoespecífica de Quercus ilex subsp. ballota con sotobosque de } \\
\text { gramíneas }\end{array}$ \\
\hline 6 & Dehesa de encina & $\begin{array}{l}\text { Formación arbórea muy abierta y monoespecífica de Quercus ilex subsp. ballota muy } \\
\text { antropizada }\end{array}$ \\
\hline 7 & Enebral & Formación arbórea cerrada y monoespecífica de Juniperus oxycedrus subsp. badia \\
\hline 8 & Enebral con matorral leguminoso & $\begin{array}{l}\text { Formación arbórea abierta y monoespecífica de Juniperus oxycedrus subsp. badia con } \\
\text { sotobosque denso de Cytisus multiflorus y Lavandula stoechas }\end{array}$ \\
\hline 9 & Matorral leguminoso con enebro & $\begin{array}{l}\text { Formación arborescente muy abierta y monoespecífica de Juniperus oxycedrus subsp. badia con } \\
\text { sotobosque denso de Cytisus multiflorus y Lavandula stoechas }\end{array}$ \\
\hline 10 & Alcornocal con encina & $\begin{array}{l}\text { Formación arbórea cerrada dominada por Quercus suber acompañada puntualmente por Quercus } \\
\text { ilex subsp. ballota }\end{array}$ \\
\hline 11 & Alcornocal con matorral de jara & $\begin{array}{l}\text { Formación arbórea abierta y monoespecífica de Quercus suber con sotobosque denso dominado } \\
\text { por Cistus ladanifer }\end{array}$ \\
\hline 12 & Quejigar de umbría & Formación arbórea cerrada y monoespecífica de Quercus faginea sobre vertientes de umbría \\
\hline 13 & Cornicabral de solana & $\begin{array}{l}\text { Formación arborescente abierta y monoespecífica de Pistacia terebinthus sobre vertientes de } \\
\text { solana }\end{array}$ \\
\hline 14 & Rebollar adehesado & Formación arbórea muy abierta y monoespecífica de Quercus pyrenaica muy antropizada \\
\hline 15 & Fresneda con sauces & $\begin{array}{l}\text { Formación arbórea abierta dominada por Fraxinus angustifolia acompañada puntualmente por } \\
\text { Salix fragilis, Salix atrocinerea y Salix salviifolia }\end{array}$ \\
\hline 16 & Matorral leguminoso & Formación arbustiva densa de Cytisus scoparius, Cytisus multiflorus y Genista hystrix \\
\hline 17 & Jaral & Formación arbustiva densa de Cistus ladanifer \\
\hline 18 & Cantuesar & Formación arbustiva densa de Lavandula stoechas \\
\hline 19 & Berceal & Formación herbácea densa de Stipa gigantea \\
\hline
\end{tabular}

Elaboración propia.

en función de los factores ambientales se representan las distintas comunidades vegetales: amarillo (serie de la encina), amarillo anaranjado (del enebro), naranja (del alcornoque), rojo anaranjado (de la cornicabra), verde amarillento (del quejigo), marrón (del rebollo) y azul (del fresno). Los colores planos indican una estructura arbórea cerrada, mientras que las tramas lineales representan estructuras arbóreas abiertas (líneas equidistantes) o muy abiertas (líneas de color más separadas). Las formaciones arbustivas y herbáceas se cartografían mediante una trama de puntos al tresbolillo. Por último, para las formaciones antrópicas se utilizan el gris (pastizales) y el blanco (cultivos). Se incluye la división parcelaria cuando se encuentra cercada por muros de piedras, entre los que se intercalan vetustos ejemplares de encina $y$, en menor medida, enebro, rebollo y alcornoque (Fig. 2).
A partir del análisis del mapa de vegetación elaborado se realiza la clasificación biogeográfica del inventario. Esta clasificación es jerárquica y sigue un criterio ecológico y paisajístico. El elemento básico lo constituye la comunidad vegetal, cada una de las cuales guarda relación con una formación vegetal encabezada por una o varias especies con representatividad territorial. Se han diferenciado 11 comunidades vegetales: encinar, enebral, alcornocal, quejigar, cornicabral, rebollar, fresneda, matorral de leguminosas, jaral, cantuesar y berceal. Cada una de ellas se identifica mediante un código alfabético y se acompaña de la serie de vegetación a la que pertenece (RIVAS-MARTÍNEZ, 1987) y su denominación local (Cuadro V).

Las comunidades vegetales presentan discontinuidades en la estructura fruto de las propias variaciones es- 
CUADRo VII. Organización de los niveles jerárquicos de las unidades de paisaje vegetal. Grandes unidades de paisaje

\begin{tabular}{|c|c|c|c|}
\hline Código & Denominación & Piso bioclimático & Tipología biogeográfica \\
\hline I & Penillanura & Piso Supramediterráneo & Sector Salmantino \\
\hline II & Garganta fluvial & Piso Mesomediterráneo & Sector Lusitano duriense (Subsector Ribaduriense) \\
\hline
\end{tabular}

Elaboración propia.

CUADRO VIII. Listado de Lugares de Interés Biogeográfico (LIB)

\begin{tabular}{|c|c|c|c|c|c|}
\hline \multirow[b]{2}{*}{ LIB } & \multirow[b]{2}{*}{ Nombre } & \multicolumn{3}{|c|}{ Códigos biogeográficos } & \multirow[b]{2}{*}{ Tipo de LIB } \\
\hline & & $\begin{array}{c}\text { Grandes unidades } \\
\text { de paisaje }\end{array}$ & $\begin{array}{c}\text { Comunidades } \\
\text { vegetales }\end{array}$ & $\begin{array}{c}\text { Facies de } \\
\text { vegetación }\end{array}$ & \\
\hline Núm. 1 & Quejigar de Peña la Galga & II & $\mathrm{D}, \mathrm{G}$ & 12,15 & Lugar singular \\
\hline Núm. 2 & Rebollar adehesado de Badilla & I & $\mathrm{F}, \mathrm{A}, \mathrm{G}, \mathrm{H}$ & 14,16 & Lugar representativo \\
\hline Núm. 3 & Enebral de Cozcurrita & II, I & $\mathrm{B}, \mathrm{H}, \mathrm{J}, \mathrm{G}$ & $7,8,9,18,15$ & Lugar representativo \\
\hline Núm. 4 & Cornicabral del Carrascón & II & $\mathrm{E}, \mathrm{G}$ & 13,15 & Elemento singular \\
\hline Núm. 5 & Encinar-enebral del Cueto & II & $\mathrm{A}, \mathrm{B}, \mathrm{G}$ & $2,7,5,15$ & Lugar representativo \\
\hline Núm. 6 & Fresneda de las Lastras de Aguas Bravas & II & $\mathrm{G}, \mathrm{K}$ & 15,19 & Elemento representativo \\
\hline Núm. 7 & Dehesa de encina de Fariza & I & $A, G$ & 6,15 & Lugar representativo \\
\hline Núm. 8 & Encinar-alcornocal de la Setera & II, I & $\mathrm{A}, \mathrm{C}$ & $1,10,3$ & Lugar representativo \\
\hline Núm. 9 & Alcornocal de Valduyán & I & $\mathrm{C}, \mathrm{I}$ & 11,17 & Lugar singular \\
\hline Núm. 10 & Encinar de Pinilla de Fermoselle & II, I & $\mathrm{A}, \mathrm{I}$ & $1,2,4,17$ & Lugar representativo \\
\hline
\end{tabular}

Elaboración propia.

paciales en las condiciones ambientales o derivadas de acciones antrópicas. Así surgen las facies de vegetación, subunidades diferenciadas por criterios fisonómicos y florísticos. En algunas comunidades vegetales pueden distinguirse varias facies de vegetación (seis del encinar, tres del enebral, dos del alcornocal), mientras que en otras una única facies representa a la propia comunidad (quejigar de umbría, cornicabral de solana, rebollar adehesado, fresneda de ribera con sauces, matorral de leguminosas, jaral, cantuesar y berceal). Del mismo modo, a cada una de estas facies de vegetación se le ha asignado un código numérico (arábigo) y se indica la estructura fisonómica y composición florística que la caracteriza (Cuadro VI).

Las facies de vegetación puestas en relación engloban unidades de mayor tamaño que aportan contexto al paisaje, definiendo las grandes unidades de paisaje. Se trata de pasar de un nivel de análisis detallado y de gran heterogeneidad, a otro a menor escala y homogéneo, en el que las piezas elementales se articulan espacialmente para dotar de entidad a las unidades mayores. Estas grandes unidades de paisaje están determinadas por la incidencia que los condicionantes de carácter más general tienen sobre la vegetación. Se diferencian así dos grandes unidades derivadas de la singular configuración geomorfológica, cuya trascendencia en el resto de los factores geográficos ha quedado suficientemente referida. Estas dos grandes unidades son la penillanura y la garganta fluvial, y están vinculadas a pisos bioclimáticos y sectores biogeográficos diferenciados. Se identifican ahora mediante un código numérico romano (Cuadro VII).

\section{INVENTARIO Y DESCRIPCIÓN DE LUGARES DE INTERÉS BIOGEOGRÁFICO (LIB)}

La selección de Lugares de Interés Biogeográfico (LIB) debe hacerse siguiendo criterios de representatividad y singularidad, aplicados a lugares o elementos biogeográficos. Resultado de esta combinación se generan cuatro tipos de LIB: lugares representativos, lugares singulares, elementos representativos y elementos singulares. Los LIB serán lugares cuando se trate de comunidades vegetales con una entidad espacial considerable, mientras que elementos serán aquellas de extensión reducida o individualizadas. A la vez, podrán ser representativos si se trata de comunidades vegetales típicas o signifi- 


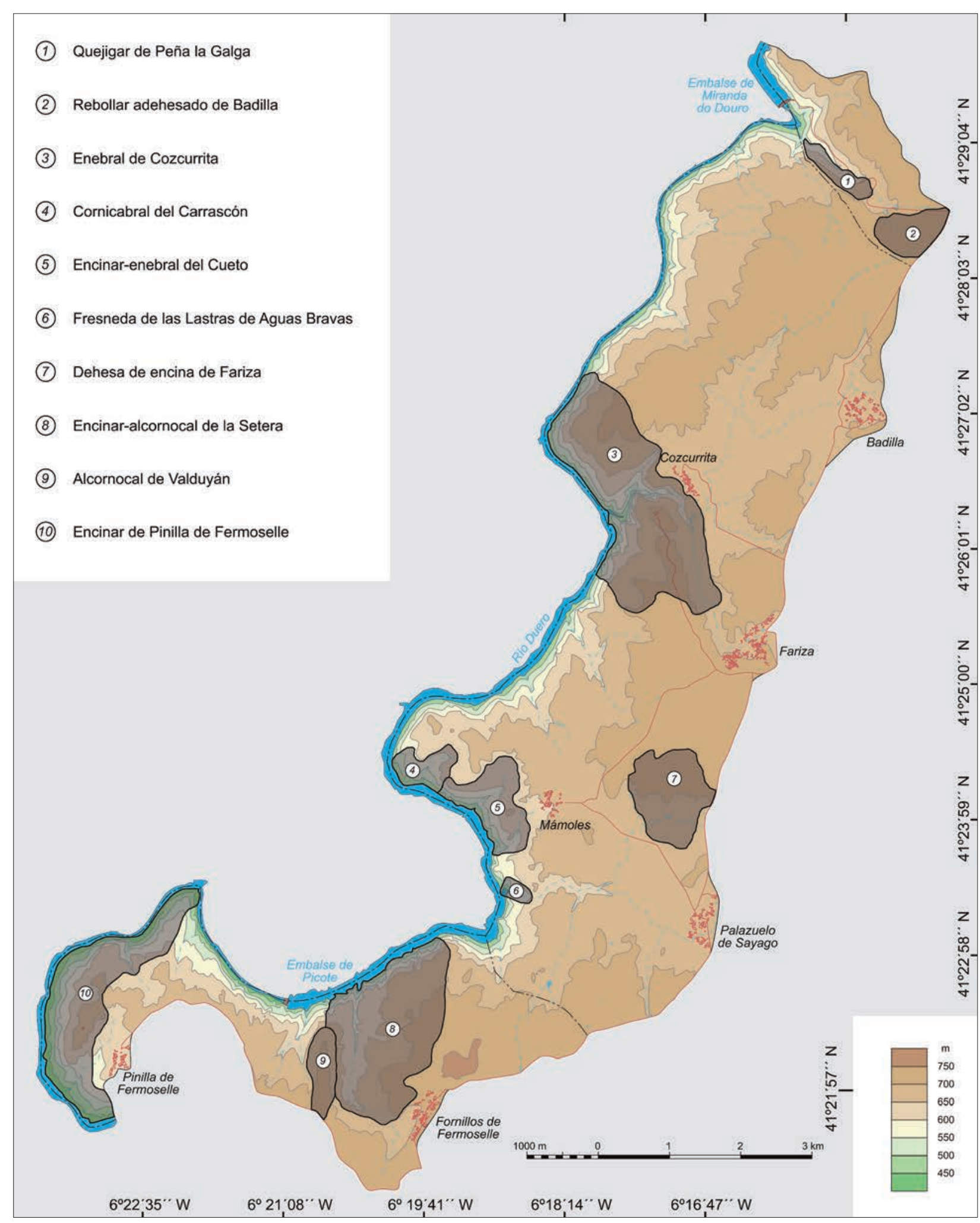

FIG. 3. Mapa de localización e inventario de los Lugares de Interés Biogeográfico (LIB). Elaboración propia a partir de la base topográfica del IGN. 
CUADRO IX. Ficha descriptiva del LIB núm. 9: Alcornocal de Valduyán

\begin{tabular}{|c|c|c|}
\hline \multicolumn{3}{|c|}{ LUGAR DE INTERÉS BIOGEOGRÁFICO: DESCRIPCIÓN } \\
\hline Identificación & Nombre: Alcornocal de Valduyán & Lugar: Fornillos de Fermoselle \\
\hline Situación & T. ${ }^{\circ}$ municipal: Villar del Buey & $\begin{array}{l}\text { Coordenadas: } 41^{\circ} 22^{\prime} 29,67^{\prime \prime} \mathrm{N} \text { a } 41^{\circ} 21^{\prime} 43,29^{\prime \prime} \mathrm{N}-6^{\circ} 20^{\prime} 55,25^{\prime \prime} \mathrm{W} \text { Altitud: } 680 \text { a } 720 \mathrm{~m} \\
\text { a } 6^{\circ} 20^{\prime} 38,10^{\prime \prime} \mathrm{W}\end{array}$ \\
\hline \multirow{9}{*}{ Biogeografía } & Tipo & Lugar singular \\
\hline & & Alcornocal \\
\hline & Caracteres biogeográficos & $\begin{array}{l}\text { Formación arbórea abierta y monoespecífica de Quercus suber con sotobosque denso } \\
\text { dominado por Cistus ladanifer. }\end{array}$ \\
\hline & Estructura fisonómica & $\begin{array}{l}\text { Estructura pluriestrata dominada por el alcornoque en los estratos arbóreo }(50-75 \%) \text {, } \\
\text { arborescente }(25-49 \%) \text { y arbustivo (menos del } 10 \%) \text { y por la jara en los estratos susbar- } \\
\text { bustivo }(10-24 \%) \text { y herbáceo }(25-49 \%) \text {. }\end{array}$ \\
\hline & Composición florística & $\begin{array}{l}\text { El alcornoque domina de forma monoespecífica los estratos arbóreo (50-75\%), arbores- } \\
\text { cente (25-49\%) y arbustivo (menos del } 10 \%) \text {, al igual que la jara el estrato subarbustivo } \\
(10-24 \%) \text {. Entran a formar parte del estrato herbáceo, además del alcornoque (menos } \\
\text { del } 10 \% \text { y la jara (entre } 10 \text { y } 24 \% \text { ), el cantueso (entre } 10 \text { y } 24 \% \text { ), el piorno, el tomillo } \\
\text { blanco, el torvisco y el jaguarcillo (menos del } 10 \% \text { cada uno de estos cuatro últimos). }\end{array}$ \\
\hline & Dinámica de la vegetación & $\begin{array}{l}\text { Los estratos dominados por el alcornoque presentan una dinámica estable ligada al apro- } \\
\text { vechamiento humano del corcho. Los estratos inferiores están condicionados por los tra- } \\
\text { tamientos silvícolas que se realizan para mantener limpio el sotobosque y airear el suelo. }\end{array}$ \\
\hline & Interés principal & Formación monoespecífica de alcornoque vinculada al sustrato litológico sedimentario. \\
\hline & Interés secundario & Paisaje de honda raigambre cultural ligado a la explotación tradicional del corcho. \\
\hline & Atribución del LIB & Alcornocal de la serie mesomediterránea Sanguisorbo hybridae-Querceto suberis. \\
\hline \multirow{9}{*}{ Usos } & Contenido cultural & $\begin{array}{l}\text { Explotación del corcho. Restos de castros prerromanos. Localidad de Fornillos de Fer- } \\
\text { moselle (iglesia renacentista, ermita, hornos ceramistas, crucero, caserío de mampostería } \\
\text { de granito fino, fuente romana, potro para elaborar varas de los arados, moral centena- } \\
\text { ria). Camino de los Arrieros. Habla sayaguesa. Romances cantados. }\end{array}$ \\
\hline & Accesibilidad & Muy buena: carretera y pista. \\
\hline & Grado de interés & Alto: científico-didáctico y paisajístico-estético. \\
\hline & Estado de conservación & Bueno. \\
\hline & Usos actuales & $\begin{array}{l}\text { Actividades agrarias (silvicultura del alcornoque, ganadería ovina y caprina, apicultura). } \\
\text { Senderismo-excursionismo (etapa } 30 \text { del GR 14, PR Hornos de Rita la Encina, PR Molde } \\
\text { de arados). }\end{array}$ \\
\hline & Comunicaciones & $\begin{array}{l}\text { Carretera ZA-L- } 2215 \text { y pista que recorre el interior del alcornocal y que posteriormente } \\
\text { desciende en forma de senda hasta el río Duero. }\end{array}$ \\
\hline & Infraestructuras & Carretera y pista. Servicios turísticos en Fornillos de Fermoselle. \\
\hline & Impactos & $\begin{array}{l}\text { Incendio reciente en las proximidades ( } 27 \text { de agosto de 2017). Plagas de insectos y hon- } \\
\text { gos que provocan la seca de alcornoques. }\end{array}$ \\
\hline & Situación legal & $\begin{array}{l}\text { Zona de Uso Compatible de Medio Natural (ZUC) establecida en el PORN del Espacio } \\
\text { Natural Arribes del Duero (2001). }\end{array}$ \\
\hline
\end{tabular}

Elaboración propia.

cativas de entre otras muchas de similares características, o bien serán singulares si son especiales o excepcionales.

A tenor de este criterio de representatividad y singularidad aplicado a lugares y elementos de interés biogeográfico se han seleccionado diez LIB, donde están presentes todos los niveles jerárquicos establecidos en la fase de clasificación de las unidades de paisaje vegetal a partir de su representación cartográfica (Cuadro VIII). Cada LIB destaca por unos valores biogeográficos concretos, reconocidos de forma detallada durante la fase de trabajo de campo.

Tras la selección se procede a la caracterización del espacio catalogado como LIB. Se trata de recoger todos los aspectos esenciales desde el punto de vista de sus valores biogeográficos, así como aquellos otros añadidos y relacionados con su posible uso y gestión. Se ha aplicado 
CUADRO X. Evaluación de los valores científicos o intrínsecos

\begin{tabular}{|c|c|c|}
\hline Valores científicos & Definición & Escala de puntuación \\
\hline Diversidad vegetal & $\begin{array}{l}\text { Núm. de comunidades vegetales que componen } \\
\text { el LIB }\end{array}$ & 1 punto por cada comunidad vegetal presente hasta un máximo de 5 \\
\hline Riqueza florística & Núm. de especies vegetales que integran el LIB & $\begin{array}{l}\text { 1. } 1 \text { especie } \\
\text { 2. 2-9 especies } \\
\text { 3. } 10-19 \text { especies } \\
\text { 4. 20-39 especies } \\
\text { 5. } 40 \text { o más especies }\end{array}$ \\
\hline Representatividad & $\begin{array}{l}\text { Porcentaje de especies vegetales presentes en } \\
\text { el LIB respecto al total del óptimo de la serie de } \\
\text { vegetación a la que representa }\end{array}$ & $\begin{array}{l}\text { 1. Menos de un } 20 \% \\
\text { 2. } 20-39 \% \\
\text { 3. } 40-59 \% \\
\text { 4. } 60-79 \% \\
\text { 5. Más de un } 80 \%\end{array}$ \\
\hline Estructura vertical & Núm. de estratos verticales que componen el LIB & 1 punto por cada estrato representado hasta un máximo de 5 \\
\hline Cobertura arbolada & Grado de recubrimiento arbóreo en el LIB & $\begin{array}{l}\text { 1. Extremadamente abierta: menos de un } 10 \% \\
\text { 2. Muy abierta: } 10-24 \% \\
\text { 3. Abierta: } 25-49 \% \\
\text { 4. Semiabierta: } 50-75 \% \\
\text { 5. Cerrada: más de un } 75 \%\end{array}$ \\
\hline Madurez & $\begin{array}{l}\text { Grado de naturalidad que posee el LIB en } \\
\text { función de la mayor o menor cercanía a la } \\
\text { comunidad clímax }\end{array}$ & $\begin{array}{l}\text { 1. Herbazales y matorrales abiertos de porte bajo } \\
\text { 2. Matorrales cerrados de porte alto } \\
\text { 3. Bosques antropogénicos } \\
\text { 4. Bosques preclimácicos } \\
\text { 5. Bosques, matorrales y herbazales climácicos }\end{array}$ \\
\hline Singularidad vegetal & $\begin{array}{l}\text { Núm. de especies vegetales raras, endémicas, } \\
\text { relícticas y/o finícolas presentes en el LIB }\end{array}$ & $\begin{array}{l}\text { 1. } 1 \text { especie } \\
\text { 2. 2-3 especies } \\
\text { 3. } 4-5 \text { especies } \\
\text { 4. 6-10 especies } \\
\text { 5. Más de } 10 \text { especies }\end{array}$ \\
\hline Flora amenazada & $\begin{array}{l}\text { Núm. de especies vegetales incluidas en el } \\
\text { catálogo regional de flora protegida que se } \\
\text { encuentran en el LIB }\end{array}$ & $\begin{array}{l}\text { 1. } 1 \text { especie } \\
\text { 2. } 2-3 \text { especies } \\
\text { 3. } 4-5 \text { especies } \\
\text { 4. } 6-10 \text { especies } \\
\text { 5. Más de } 10 \text { especies }\end{array}$ \\
\hline Función ecológica & $\begin{array}{l}\text { Tipo de estructura vertical y recubrimiento } \\
\text { vegetal que contribuye a la estabilización de } \\
\text { los procesos biológicos, edafogenéticos y } \\
\text { morfogenéticos que tienen lugar en el LIB }\end{array}$ & $\begin{array}{l}\text { 1. Vegetación arbustiva o herbácea abierta } \\
\text { 2. Vegetación arbórea abierta con sotobosque abierto } \\
\text { 3. Vegetación arbustiva o herbácea cerrada } \\
\text { 4. Vegetación arbórea cerrada con sotobosque abierto } \\
\text { 5. Vegetación arbórea cerrada o abierta con sotobosque cerrado }\end{array}$ \\
\hline Valor etnobotánico & $\begin{array}{l}\text { Núm. de especies con valor etnobotánico dentro } \\
\text { del LIB }\end{array}$ & $\begin{array}{l}\text { 1. } 1 \text { especie } \\
\text { 2. 2-4 especies } \\
\text { 3. } 5-9 \text { especies } \\
\text { 4. } 10-19 \text { especies } \\
\text { 5. Más de } 20 \text { especies }\end{array}$ \\
\hline Puntuación total & Media ponderada de 10 puntos & Máximo 50 \\
\hline
\end{tabular}

Elaboración propia.

para tal fin una ficha descriptiva que se ha sido elaborada para cada LIB (Cuadro IX).

El LIB núm. 1 es una extensa mancha de quejigo bastante pura y densa enclavada en la vertiente de umbría del profundo y estrecho valle abierto por el arroyo de Peña la Galga en su vertiginoso descenso desde la penillanura al río Duero. Su singularidad está determinada por tratarse de una de las escasas masas de esta especie en los Arribes del Duero zamoranos. El LIB núm. 2 es representativo de las grandes masas de rebollo que se extienden penillanura adentro. Se trata de una comunidad vegetal profundamente alterada por la intervención humana, 
donde robustos rebollos adehesados se diseminan entre tierras de labor. El LIB núm. 3 engloba una de las mejores representaciones nacionales de bosque constituido por el enebro de la miera, no en vano está considerado el más extenso de Europa (LópEz y otros; 2009, p. 105). Destaca por su inusitado carácter boscoso y el porte arbóreo de una formación vegetal catalogada en principio como matorral arborescente (MONTESINOS y GARCÍA, 2009 $)^{16}$. El LIB núm. 4 está constituido por una reducida masa de cornicabra emplazada en una suave ladera de la garganta fluvial orientada al sur. Su peculiaridad está determinada por la poca frecuencia con la que esta especie es capaz de configurar manchas más o menor puras, de hecho, se trata del único rodal presente en los Arribes del Duero zamoranos. El LIB núm. 5 representa un fenómeno frecuente en esta encrucijada biogeográfica que son los Arribes del Duero. Nos referimos a las formaciones mixtas que se generan entre las dos especies que con mayor asiduidad medran por las escarpadas vertientes de la garganta fluvial, la encina y el enebro. El LIB núm. 6 se corresponde con una de las típicas fresnedas con sauces que recorren las riberas de los arroyos. Amén de su elevado grado de naturalidad, se encuentra flanqueada por un conjunto de saltos de agua, lo que origina un paisaje de enorme belleza. El LIB núm. 7 es un encinar adehesado, representativo de tantos otros que se extienden por la penillanura zamorano-salmantina. El LIB núm. 8 se ubica en el amplio valle del arroyo de la Setera, donde se desarrolla un dilatado encinar que en su parte superior se entremezcla con alcornoques, configurando un peculiar paisaje entre bolos graníticos. El LIB núm. 9 constituye uno de los lugares más singulares, por cuanto la presencia del alcornoque está vinculada a los exiguos depósitos terciarios que tapizan someramente algunos sectores de la penillanura cercanos al río Tormes. La explotación del corcho ha favorecido la conservación de un paisaje con honda raigambre cultural (GUERRA, 2015) ${ }^{17}$. Y el LIB núm. 10 representa una de las grandes formaciones de encinar que dominan los Arribes del Duero zamoranos, desde las partes cacuminales de la penillanura hasta las orillas del río Duero. Presenta una gran variedad interna

\footnotetext{
${ }^{16}$ Los enebrales de Juniperus oxycedrus L. en Cozcurrita fueron objeto de un estudio detallado, donde se analizó la distribución, caracterización fitosociológica y dinámica en relación con los usos. Los resultados fueron presentados al IX Congreso Español de Biogeografía y publicados en las correspondientes actas (MARINO y otros, 2016).

${ }^{17}$ El paisaje y la conservación de este alcornocal a través de su explotación en Fornillos de Fermoselle se analizaron en una comunicación presentada al X Congreso Español de Biogeografía y publicada en el correspondiente libro de actas (MARINO y otros, 2018a).
}

en cuanto a densidad arbórea y composición florística de los estratos inferiores (Fig. 3).

\section{VALORACIÓN DE LIB}

Tras la pormenorizada descripción de los LIB en sus respectivas fichas, se efectúa la evaluación. Esta debe intentar obtener la máxima objetividad posible desde la integración de una triple valoración: valor científico o intrínseco, valor cultural o añadido y valor de uso y gestión. Los valores culturales y de uso y gestión se califican siguiendo la misma escala de puntuación elaborada para la valoración de Lugares de Interés Geomorfológico (LIG) (MARINO y otros, 2017a). Los valores científicos requieren de una nueva escala de puntuación adaptada a los valores puramente biogeográficos (Cuadro X).

Los LIB que alcanzan un alto valor científico (superior a 7,5$)$ son, por este orden, el encinar de Pinilla de Fermoselle $(8,4)$, el enebral de Cozcurrita $(8,2)$, el encinar-alcornocal de la Setera $(8,2)$ y el encinar-enebral del Cueto (8). En todos los casos, se trata de las masas boscosas más densas y extensas ubicadas en la garganta fluvial del Duero. Con un valor científico medio-alto (entre 7 y 5) se encuentran el quejigar de Peña la Galga $(6,4)$, el cornicabral del Carrascón $(5,6)$, el alcornocal de Valduyán $(5,6)$, el rebollar adehesado de Badilla $(5,6)$ y la fresneda de las Lastras de Aguas Bravas $(5,4)$. En este caso, se corresponden con formaciones vegetales más reducidas o alteradas por la intervención humana. Por último, tan solo hay un LIB con un valor científico bajo (inferior a 3,5), en concreto, la dehesa de encina de Fariza $(3,2)$, debido a la intensa antropización del paisaje vegetal.

En lo que respecta a los valores culturales o añadidos, todos los LIB, excepto uno, presentan un valor alto. A su elevado valor contribuye, de forma general, la presencia más o menos cercana de núcleos de población con un importante número de elementos patrimoniales, culturales o históricos. Asimismo, al tratarse en muchos casos de lugares enclavados en las inmediaciones de la garganta fluvial del Duero, la consideración escalar paisajística y estética es mayor. Por último, también aportan un valor significativo los recursos turísticos generados por los órganos de gestión del Parque Natural (recorridos señalizados, paneles informativos, miradores, centros de interpretación y oficinas de turismo).

Para finalizar, el potencial de uso y gestión es, en todos los LIB, medio-alto. La accesibilidad es generalmente buena. El grado de fragilidad de muchos de los lugares permite un uso controlado. La vulnerabilidad es el va- 
CUADRO XI. Valoración de los Lugares de Interés Biogeográfico (LIB)

\begin{tabular}{|c|c|c|c|c|c|c|}
\hline \multirow[b]{2}{*}{ Núm. LIB } & \multirow[b]{2}{*}{ Nombre } & \multirow[b]{2}{*}{ Tipo } & \multicolumn{4}{|c|}{ Valoración } \\
\hline & & & Intrínseca & Añadida & Uso y gestión & Global \\
\hline 1 & Quejigar de Peña la Galga & LS & 6,4 & 8 & 6 & 6,8 \\
\hline 2 & Rebollar adehesado de Badilla & LR & 5,6 & 7 & 7 & 6,5 \\
\hline 3 & Enebral de Cozcurrita & LR & 8,2 & 8,2 & 6,5 & 7,6 \\
\hline 4 & Cornicabral del Carrascón & ES & 5,6 & 6,5 & 5 & 5,7 \\
\hline 5 & Encinar-enebral del Cueto & LR & 8 & 7,6 & 6,5 & 7,3 \\
\hline 6 & Fresneda de las Lastras de Aguas Bravas & ER & 5,4 & 7,4 & 5,5 & 6,1 \\
\hline 7 & Dehesa de encina de Fariza & LR & 3,2 & 7,4 & 6,5 & 5,3 \\
\hline 8 & Encinar-alcornocal de la Setera & LR & 8,2 & 8 & 6 & 7,4 \\
\hline 9 & Alcornocal de Valduyán & LS & 5,6 & 7,7 & 7,5 & 6,9 \\
\hline 10 & Encinar de Pinilla de Fermoselle & LR & 8,4 & 8 & 6,5 & 7,6 \\
\hline
\end{tabular}

Elaboración propia.

lor más negativo, asociada a los incendios forestales. La frecuentación de estos lugares es muy moderada, por lo que el riesgo de degradación es reducido. Los impactos son poco intensos. Las condiciones de observación están limitadas, por las características orográficas, a entornos más o menos cercanos. Por último, la existencia de servicios y equipamientos cercanos para acoger usos turísticos incrementa el potencial económico de muchos LIB como recursos patrimoniales de gran valor (Cuadro XI).

\section{DIAGNOSIS Y PROPUESTAS DE USO Y GESTIÓN PARA LIB}

La evaluación de los valores científicos, culturales y de uso y gestión pone de manifiesto la relevancia que el patrimonio biogeográfico tiene en el Parque Natural de Arribes del Duero. A ello contribuye, en primer lugar, la enorme biodiversidad que hay en este espacio protegido, resultante de la interacción de los múltiples factores geográficos que intervienen en la configuración del paisaje vegetal. En segundo lugar, se añade una gran riqueza cultural vinculada al carácter de área marginal y marginada en la que se inscribe este territorio, por cuanto se ha preservado un ingente patrimonio material e inmaterial vinculado a la explotación sostenible de los recursos naturales. Por último, el excelente estado de conservación del paisaje ofrece un elevado potencial de uso y gestión como recurso científico, didáctico y ecoturístico (Fig. 4).

Por lugares, los más sobresalientes y con un mayor potencial son los LIB núms. 3, 5, 8 y 10, puesto que presentan unos valores intrínsecos y extrínsecos altos y de uso y gestión medio-alto. No obstante, otros cinco (LIB núms. 1, 2, 4, 6 y 9) simplemente presentan un valor científico algo más bajo. Todos ellos (90\% del total) se revelan como lugares idóneos donde materializar cualquier tipo de propuesta encaminada a la interpretación del patrimonio biogeográfico orientada a su aprovechamiento didáctico y ecoturístico. Es importante, por tanto, gestionar adecuadamente el flujo de visitantes y la intensidad de uso para evitar una pérdida de valores. Se propone también corregir algunos impactos presentes en alguno de los LIB, como escombreras, canteras y edificios abandonados. Del mismo modo, sería recomendable habilitar algunos pasos en zonas de alambradas vinculadas a cotos de caza, así como mejorar la accesibilidad en algunos puntos mediante una señalización más adecuada. En última instancia, sería muy interesante la creación de un centro de interpretación del patrimonio biogeográfico de los Arribes del Duero zamoranos, en alguna dependencia municipal o integrado en la propia Casa del Parque sita en el Convento de San Francisco de Fermoselle. Desde aquí podrían establecerse itinerarios interpretativos por los distintos lugares de interés biogeográfico, a través de visitas guiadas, folletos informativos o aplicaciones para móviles.

\section{CONCLUSIONES}

La incidencia de los factores geográficos, tanto físicos como antrópicos, explica la diversidad del paisaje vegetal de los Arribes del Duero zamoranos. A través de un detallado análisis biogeográfico se ha podido desen- 

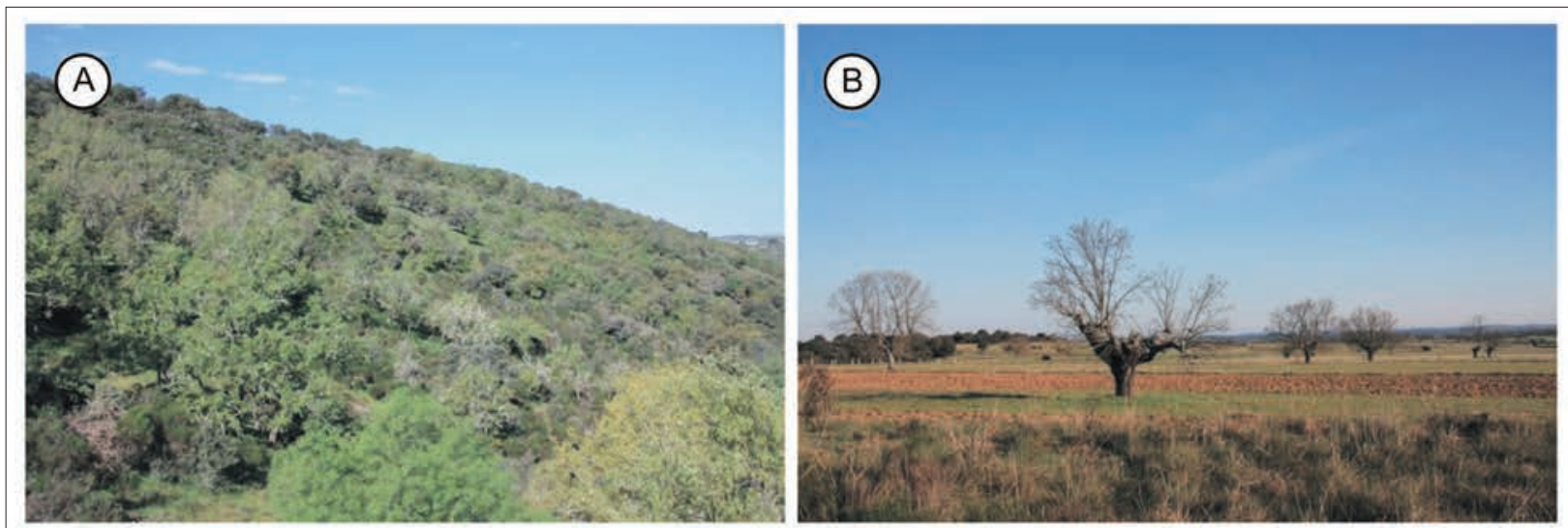

(C)
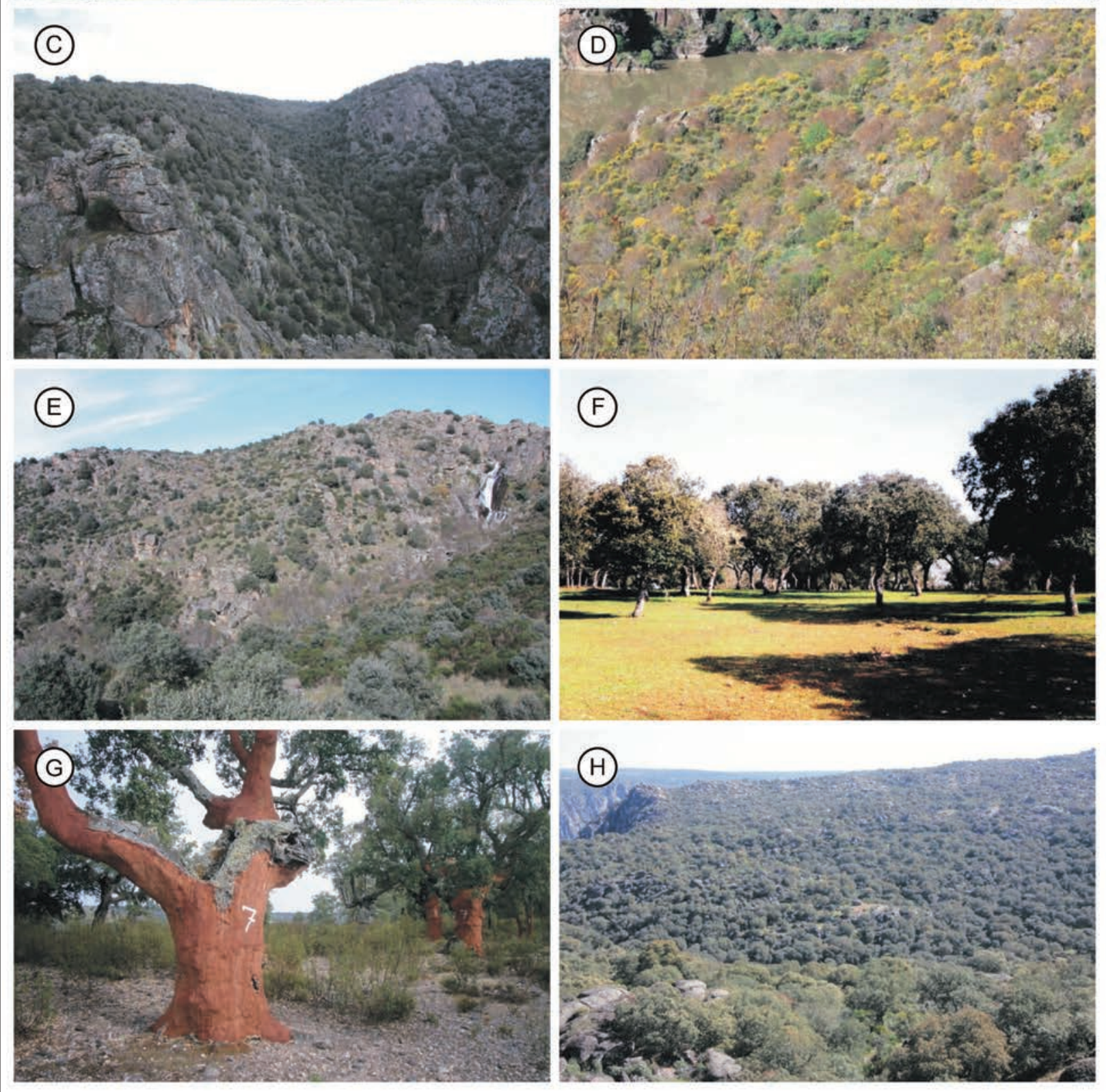

FIG. 4. Imágenes de Lugares de Interés Biogeográfico (LIB): A. Quejigar de Peña la Galga (LIB núm. 1). B. Rebollar adehesado de Badilla (LIB núm. 2). C. Enebral de Cozcurrita (LIB núm. 3). D. Cornicabral del Carrascón (LIB núm. 4). E. Fresneda de las Lastras de Aguas Bravas (LIB núm. 6). F. Dehesa de encina de Fariza (LIB núm. 7). G. Alcornocal de Valduyán (LIB núm. 9). H. Encinar-alcornocal de la Setera (LIB núm. 8). Elaboración propia. 
trañar la articulación espacial del complejo mosaico vegetal, sintetizado gráficamente en un mapa de unidades de paisaje vegetal a escala 1:25.000. El mapa elaborado constituye un elemento clave en la clasificación del inventario biogeográfico en niveles jerarquizados, esto es, grandes unidades de paisaje, comunidades vegetales y facies de vegetación. A partir de criterios de representatividad y singularidad aplicados a lugares o elementos con interés biogeográfico, se han seleccionado diez Lugares de Interés Biogeográfico (LIB), en los que están representados todos los niveles jerárquicos establecidos, y se han clasificado en lugares representativos, lugares singulares, elementos representativos y elementos singulares. La evaluación, efectuada desde una triple perspectiva integradora (científica, cultural y de uso y gestión), ha puesto de relevancia el potencial del patrimonio biogeográfico en los Arribes del Duero zamoranos, por cuanto nueve de los diez LIB evaluados han obtenido una valoración científica alta o media-alta, cultural alta y de uso y gestión media-alta.

Su interés científico, paisajístico, cultural, didáctico y ecoturístico convierte a los LIB en recursos patrimoniales que deben ser conocidos, protegidos y divulgados $\mathrm{y}$, en último término, puestos en uso y valor como potencialidades económicas ligadas al desarrollo sostenible de áreas rurales deprimidas. En función de los valores intrínsecos, extrínsecos y de uso y gestión se han determinado unas pautas de uso de cada LIB, que en la mayoría de los casos pasa por la interpretación del patrimonio biogeográfico orientado hacia su aprovechamiento didáctico y ecoturístico. Así, el método de trabajo aplicado para el inventario y valoración de LIB, desarrollado a partir de trabajos previos en el campo del patrimonio geomorfológico (MARINO y otros, 2017a) y adaptado aquí al ámbito biogeográfico, ha demostrado sus posibilidades como método generador de recursos territoriales de utilidad turística, educativa y ambiental. A los nueve LIG se suman ahora diez LIB en la misma zona de estudio, una pequeña porción del Parque Natural de Arribes del Duero enclavado en la comarca zamorana de Sayago, que no llega a representar el $6 \%$ de la extensión total del espacio protegido. Este dato pone de manifiesto la enorme potencialidad tanto del espacio natural en cuestión, como del propio método de trabajo aplicado.

\section{BIBLIOGRAFÍA}

Arozena Concepción, M. E., y P. Molina Holgado (2000): «Estructura de la vegetación», en G. Meaza (dir.): Metodología y práctica de la Biogeografía, Ediciones del Serbal, Barcelona, pp. 77-147.

BeAto BeRguA, S. (2018): El patrimonio natural de la Sierra del Aramo (Montaña Central Asturiana) y la evolución de su paisaje, tesis doctoral inédita, Universidad de Oviedo, 596 pp.

- J. L. Marino Alfonso y M. A. Poblete PiedrabueNA (2017): «El paisaje vegetal y los hábitats forestales de interés comunitario en la Montaña Central Asturiana», Cuadernos Geográficos, 56 (1), pp. 26-52.

Benton, M. J. (2001): «Biodiversity on land and in the sea», Geological Journal, 36 (3-4), pp. 211-230.

Braun-BlanQueT, J. (1979): Fitosociología. Bases para el estudio de las comunidades vegetales, Blume, Madrid, 820 pp.

CABo Alonso, A. (1956): «El colectivismo agrario en Tierra de Sayago», Estudios Geográficos, 65, pp. 593-658.

Cadiñanos Aguirre, J. A., G. Meaza Rodríguez y P. J. LOZANO VALENCIA (2002): «Valoración del interés y de la prioridad de conservación de bosques y comunidades preforestales de Larra (Alto Pirineo Navarro)», en M. E. Arozena Concepción, E. Beltrán Yanes y P. Dorta Antequera (coords.): La Biogeografía: ciencia geográfica y ciencia biológica. Actas del II Congreso Español de Biogeografía, Universidad de La Laguna, Tenerife, pp. 354-365.

CAlOnge CANO, G. (1990): «La excepcionalidad climática de los arribes del Duero», Ería, 21, pp. 45-59.

Constanza, R., R. D’Arge, R. DE Groot, S. FArber, M. DE GRASSO, B. HANNON, K. LiMBURG, S. NAEEM, R. V. O’Neil, J. PARUelo, R. G. Rasking, P. SutTON y M. VAN DER BELT (1997): «The value of the world's ecosystem services and natural capital», $\mathrm{Na}$ ture, 387, pp. 253-260.

Costa Martínez, J. (1902): «Concejo colectivista de Sayago», en J. Costa Martínez (dir.): Derecho consuetudinario y economía popular de España, vol. II (1981), Guara, Zaragoza, pp. 21-35.

Crespo Alonso, J. (1968): El paisaje agrario de los Arribes del Duero, Instituto Juan Sebastián Elcano (CSIC), Madrid, 143 pp.

DECRETO 63/2017, de 14 de junio, por el que se crean el Catálogo de Flora Protegida de Castilla y León y la figura de protección denominada Microrreserva de Flora, Boletín Oficial de Castilla y León, 119, pp. 13.197-13.204.

DíAz SANZ, M. C., y P. J. LoZANo VALENCIA (2017): «Los paisajes de dehesa de la provincia de Ciudad Real. Caracterización y valoración biogeográfica a 
través de la metodología Lanbioeva», Cuadernos Geográficos, 56 (3), pp. 187-206.

Duchaufour, P. (1984): Edafología: Edafogénesis y clasificación, Masson, Barcelona, 493 pp.

Gallego Carricajo, E., y Á. Gallego Carricajo (2008): Usos, tradiciones y conocimientos de las plantas por las gentes de Sayago, Aderisa, Bermillo de Sayago (Zamora), 119 pp.

GARcía FERnÁndeZ, J. (1986): El clima en Castilla y León, Ámbito, Valladolid, 370 pp.

Gaussen, H. (1966): «Emploi de la couleur dans les cartes de végétation», Pirineos, 79-80, pp. 201-216.

GonzÁlez Amuchastegui, M. J., E. SERrano CAÑADAS y M. GONZÁlEZ GARCíA (2014): «Lugares de interés geomorfológico, geopatrimonio y gestión de espacios naturales protegidos: el Parque Natural de Valderejo (Álava, España)», Revista de Geografía Norte Grande, 59, pp. 45-64.

GonZÁlez BERNÁLDEZ, F. (1992): «La frutalización del bosque mediterráneo», en Paisaje Mediterráneo, Electa, Milán, pp. 136-141.

GonzÁlez TruebA, J. J. (2006): El Macizo Central de los Picos de Europa: geomorfología y sus implicaciones geoecológicas en la alta montaña cantábrica, tesis doctoral inédita, Universidad de Cantabria, Santander, $819 \mathrm{pp}$.

- y E. SERRANO CAÑAdAS (2008): «La valoración del patrimonio geomorfológico en espacios naturales protegidos. Su aplicación al Parque Nacional de los Picos de Europa», Boletín de la AGE, 47, pp. 175-194.

Guerra Velasco, J. C. (2015): «La industria corchotaponera en el noroeste de España: origen y evolución de una actividad de perfil artesanal», Revista de Historia Industrial, 57, pp. 55-86.

JORDÁ PARDO, J. F. (2006): Rocas, formas y fósiles. Patrimonio geológico de la provincia de Zamora, Cuadernos de Investigación, vol. 25, Instituto de Estudios Zamoranos Florián de Ocampo (CSIC), Zamora, $145 \mathrm{pp}$.

JOVELlAR LACAMBRA, L. C. (2008): «Cartografía del hábitat potencial climático y edafoclimático de Quercus suber L. en el centro-oeste de España: efecto de la capacidad de retención de agua del suelo», Cuadernos de la Sociedad Española de Ciencias Forestales, 25, pp. 255-260.

López GómEZ, J., y A. LóPEz GóMEZ (1959): «El clima de España según la clasificación de Köppen», Estudios Geográficos, 75, pp. 167-188.

LÓPEZ LEIVA, C., J. ESPINOSA RINCÓN y J. BENGOA MARTÍNEZ DE MANDOJANA (2009). Mapa de vegetación de Castilla y León. Síntesis 1:400.000, Junta de Castilla y León, Valladolid, 159 pp.

Lozano Valencia, P. J., J. A. Cadiñanos Aguirre, M. Á. LOZANO VALENCIA, I. LATASA ZABALlos, G. MEAZA RodríGUEZ y C. MARTí LLAMBRICH (2015): «Aplicación del método de valoración biogeográfico (Lanbioeva) a ecosistemas del norte de Europa», Ería, 97, pp. 189-202.

Lozano VAlencia, P. J., G. Meaza RodríGuez, J. Pintó Fusalba, C. Martí Llambrich, J. M. PANAREDA Clopés, N. La Roca Cervigón, M. E. Arozena CONCEPCiÓn, R. BEJARANO PALMA, R. CÁMARA ARTIGAS, E. RODRÍGUEZ, B. ISRAEL, M. BOCCIO SERRANO e I. LATASA ZABALLOS (2018a): «Caracterización, inventariación y aplicación del método de Valoración Biogeográfica de paisajes vegetales (Lanbioeva) a la comarca de Collsacabra (Girona)», Estudios geográficos, vol. 79, núm. 284, pp. 7-37.

Lozano Valencia, P. J., J. A CAdiÑanos Aguirre Y G. MEAZA RodRíGUEZ (2018b): Metodología de inventariación y valoración de los paisajes vegetales, documento inédito. $40 \mathrm{pp}$.

Marino Alfonso, J. L., M. Á. Poblete Piedrabuena y S. BeAto Bergua (2016): «Los enebrales de $J u$ niperus oxycedrus L. en Cozcurrita (Parque Natural de Arribes del Duero, Zamora): distribución, caracterización fitosociológica y dinámica en relación con los usos», en J. Gómez Zotano, J. Arias García, J. A. Olmedo Cobo y J. L. Serrano Montes (eds.): Avances en Biogeografía. Áreas de distribución: entre puentes y barreras, Universidad de Granada y Tundra Ediciones, Granada, pp. 465-473.

Marino Alfonso, J. L., M. Á. Poblete Piedrabuena y S. BeATO BerguA (2017a): «Valoración del patrimonio geomorfológico de un sector del Parque Natural de Arribes del Duero (Bajo Sayago, Zamora)», Cuaternario y Geomorfología, 31 (3-4), pp. 27-50.

- (2017b): «El patrimonio vegetal en los Arribes del Duero zamoranos: las formaciones de enebral Juniperus oxycedrus L. subsp. badia (H. Gay) Debeaux», Cuadernos Geográficos, 56 (3), pp. 90-115.

- (2018a): «Paisaje y conservación del alcornocal de Fornillos de Fermoselle a través de su explotación (Parque Natural de Arribes del Duero, Zamora, España)», en R. U. Gonsálvez Rey, M. C. Díaz Sanz, J. L. García Rayego, M.A. Serrano de la Cruz Santos-Olmo y O. Jerez García (coords.): Bosque mediterráneo y humedales: paisaje, evolución y conservación. Aportaciones desde la Biogeografía, t. 1, Almud, Ediciones de Castilla-La Mancha, Ciudad Real, pp. 208-218. 
- (2018b): «Geomorfología de los Arribes del Duero zamoranos», Estudios Geográficos, vol. LXXIX, núm. 285, pp. 419-444.

- (2019): El relieve de los Arribes del Duero zamoranos y los Lugares de Interés Geomorfológico, Ediuno, Oviedo, 124 pp.

Martín Duque, J. F., J. CABAllero García y L. CARCAVILLA URQUí (2010): «Organización de información geomorfológica orientada a la ordenación y gestión de espacios naturales. El caso de Covalagua y Las Tuerces (Palencia, España)», Boletín de la Real Sociedad Española de Historia Natural Sección Biológica, 104 (1-4), pp. 71-92.

- (2012): «Geoheritage Information for Geoconservation and Geoturism Through the Categorization of Landforms in a karstic Landscape. A Case Study from Covolagua and Las Tuerces (Palencia, Spain)», Geoheritage, 4, pp. 93-108.

MARtín-SERrano GARCÍA, A. (1988): El relieve de la región occidental zamorana. La evolución geomorfológica de un borde del Macizo Hespérico, Instituto de Estudios Zamoranos Florián de Ocampo, Zamora, $311 \mathrm{pp}$.

MEAZA RodRíGUEZ, G. (2000): «Introducción», en G. Meaza (dir.): Metodología y práctica de la Biogeografía, Ediciones del Serbal, Barcelona, pp. 13-15.

- y J. A. CAdiÑAnos AguirRe (2000): «Valoración de la vegetación», en G. Meaza (dir.): Metodología y práctica de la Biogeografía, Ediciones del Serbal, Barcelona, pp. 199-272.

MONTESINOS TORRES, D., y D. GARCíA GARCÍA (2009): «5210 Matorrales arborescentes de Juniperus spp.», en E. Bermejo Bermejo y F. Melado Morillo (coord.): Bases ecológicas preliminares para la conservación de los tipos de hábitat de interés comunitario en Espa$\tilde{n} a$, Centro de publicaciones del Ministerio de Medio Ambiente, y Medio Rural y Marino, Madrid, 52 pp.

NAFría García, D. A., N. Garrido DEL PoZO, M. V. Álvarez Arias, D. CUBERo JimÉnEZ, M. FERNÁNDEZ SÁnchez, I. Villarino Barrera, A. GutiéRREZ GArcía e I. ABIA LlerA, (2013): Atlas Agroclimático de Castilla y León, Instituto Tecnológico Agrario de Castilla y León y Agencia Estatal de Meteorología, Madrid, $135 \mathrm{pp}$.

NAVARro ANDrÉs, F., y J. A. VAlle GutiÉRreZ (1987): «Castilla y León», en M. Peinado Lorca y S. RivasMartínez (eds.): La vegetación de España, Universidad de Alcalá de Henares, Madrid, pp. 117-161.

PIQUERAS, J. (2001): «El Patrimonio vegetal: Las variedades viníferas», Mètode: Anuario, 2001, pp. 55-57.
RIVAS-MARTÍNEZ, S. (1987): Memoria del mapa de series de vegetación de España 1:400.000, ICONA, Madrid, $268 \mathrm{pp}$.

RUIZ DE LA TORRE, J. (1991): «Características de la zona representada», en J. Ruiz de la Torre (dir.): Memoria de la Hoja 3-4 (Alcañices) del Mapa Forestal de España Escala 1:200.00, ICONA, Madrid, pp. 9-66.

SÁNCHEZ GóMEZ, L. A. (1991): Ganadería y comunalismo agrosilvopastoril, Caja España, Zamora, 326 pp.

SÁNCHEZ RodríGUEZ, J. A. (1984): «La vegetación leñosa de los Arribes del Duero zamoranos», Studia Zamorensia, 5, pp. 65-82.

SAntos Vicente, M., L. Delgado SÁnchez y P. BARIEGO HERNÁNDEZ (2006): Guía de las plantas silvestres de los Arribes del Duero zamoranos y su entorno, Aderisa, Bermillo de Sayago (Zamora), 287 pp.

SERRA, Ll. (2016): El patrimonio vegetal de Elda. Entre saladares y estepas del Vinalopó. Elda (Alicante), Concejalía de Medio Ambiente, Ayuntamiento de Elda. 272 pp.

Serrano Cañadas, E., y J. J. González Trueba (2005): «Assessment of geomorphosites in natural protected areas: the Picos de Europa National Park (Spain)», Géomorphologie: relief, processus, environnement, 3, pp. 197-208.

Serrano Cañadas, E., P. Ruiz Flaño, P. Arroyo PéREZ y J. J. GONZÁLEZ TRUEBA (2006): «Lugares de interés geomorfológico. Inventario y valoración aplicada al área de Tiermes Caracena (Provincia de Soria)», en A. Pérez Alberti y J. López Bedoya (eds.): Geomorfología y territorio, Actas de la IX Reunión Nacional de Geomorfología, Universidad de Santiago de Compostela, pp. 963-976.

SerRano CAÑADAs, E., y P. RuIZ Flaño (2007): «Geodiversidad: concepto, evaluación y aplicación territorial. El caso de Tiermes Caracena (Soria)», Boletín de la Asociación de Geógrafos Españoles, 45, pp. 79-98.

Serrano Cañadas, E., M. J. González AmuchasTEGui, P. Ruiz Flaño y J. J. GonzÁlez Trueba (2009): «Gestión ambiental y geomorfología: valoración de los lugares de interés geomorfológico del Parque Natural de las Hoces del Alto Ebro y Rudrón», Cuaternario y Geomorfología, 23 (3-4), pp. 65-82.

SERVICIO DE PROTECCIÓN Y CONSERVACIÓN DE LA NATURALEZA DE LA REGIÓN DE MURCIA (2009): «Patrimonio vegetal de la Región de Murcia: protección y conservación», Conservación Vegetal, 13, pp. 18-22.

SOLÉ SABARÍs, L. (1958): «Observaciones sobre la edad de la penillanura fundamental de la Meseta española 
en el sector de Zamora», Breviora Geológica Asturica, 2, pp. 3-8.

ThORNTHWAITE, C. W. (1948): «An approach toward a rational classification of climate», Geographical Review, 38, pp. 55-94.
VILCHES, J. (2007): «Patrimonio vegetal, educación para la conservación y jardines botánicos», Aula Verde: Revista de Educación Ambiental, 32, pp. 29-31.

WHITTAKER, R. H. (1972): «Evolution and measurement of species diversity», Taxón, 21, pp. 213-251. 